Provided for non-commercial research and education use. Not for reproduction, distribution or commercial use.

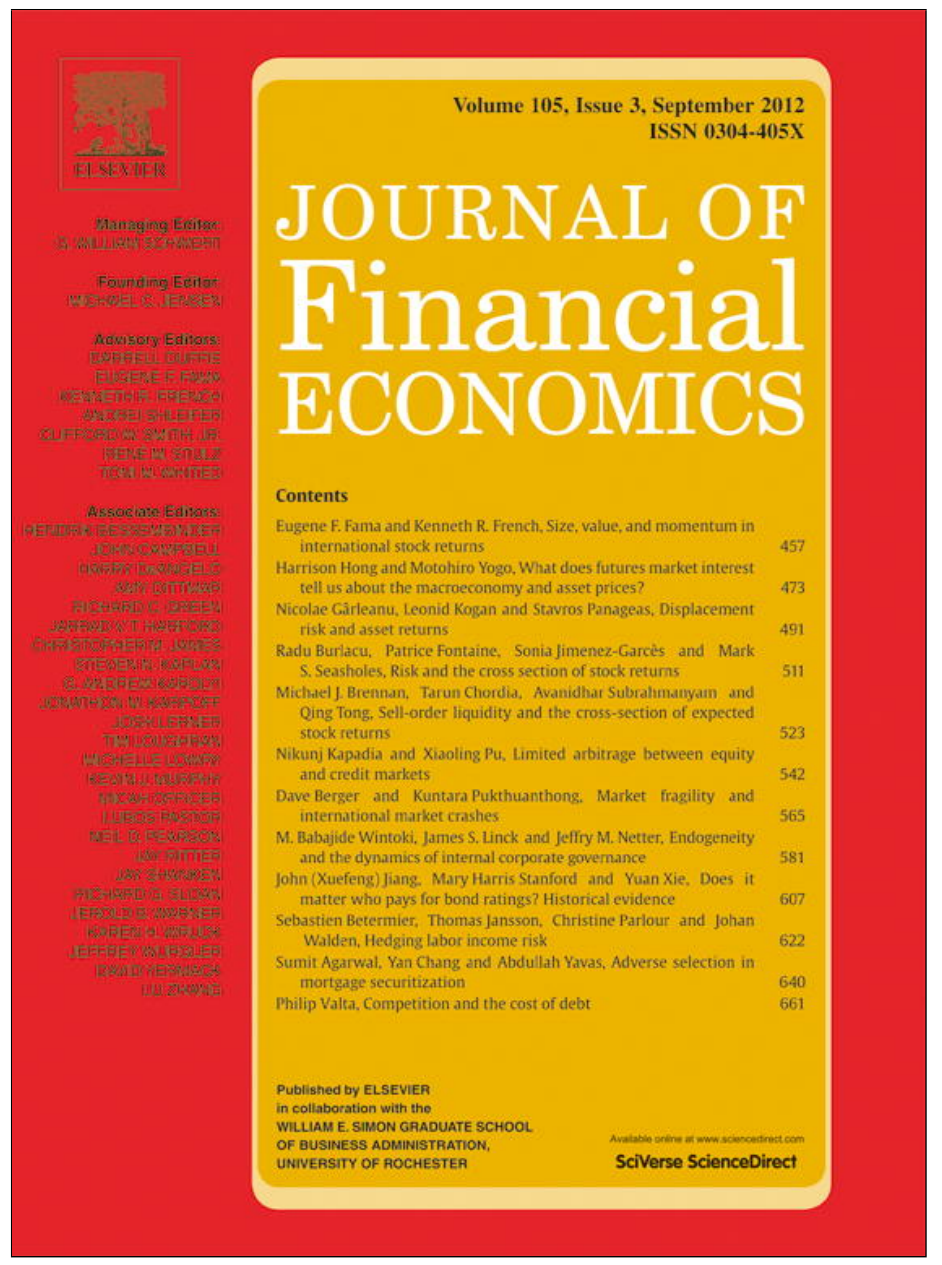

This article appeared in a journal published by Elsevier. The attached copy is furnished to the author for internal non-commercial research and education use, including for instruction at the authors institution and sharing with colleagues.

Other uses, including reproduction and distribution, or selling or licensing copies, or posting to personal, institutional or third party websites are prohibited.

In most cases authors are permitted to post their version of the article (e.g. in Word or Tex form) to their personal website or institutional repository. Authors requiring further information regarding Elsevier's archiving and manuscript policies are encouraged to visit:

http://www.elsevier.com/copyright 


\title{
Displacement risk and asset returns is
}

\author{
Nicolae Gârleanu ${ }^{\text {a,b,c,*, Leonid Kogan }}{ }^{\text {b,d,1 }}$, Stavros Panageas ${ }^{\text {b,e,2 }}$ \\ ${ }^{a}$ Haas School of Business, UC Berkeley, 545 Student Services Building, Berkeley, CA 94720-1900, USA \\ ${ }^{\mathrm{b}} \mathrm{NBER}, \mathrm{USA}$ \\ c CEPR, UK \\ d Sloan School of Management, MIT E62-636, 100 Main Street, Cambridge, MA 02142, USA \\ ${ }^{\mathrm{e}}$ University of Chicago Booth School of Business, 5807 South Woodlawn Avenue, Office 313, Chicago, IL 60637, USA
}

\section{A R T I C L E I N F O}

\section{Article history:}

Received 28 February 2011

Received in revised form

1 July 2011

Accepted 20 July 2011

Available online 17 May 2012

\section{JEL classification:}

G00

G10

G12

E21

D53

\section{Keywords:}

Consumption-based asset pricing

Displacement risk

Value premium

Equity premium

Incomplete markets

\begin{abstract}
A B S T R A C T
We study asset-pricing implications of innovation in a general-equilibrium overlappinggenerations economy. Innovation increases the competitive pressure on existing firms and workers, reducing the profits of existing firms and eroding the human capital of older workers. Due to the lack of inter-generational risk sharing, innovation creates a systematic risk factor, which we call "displacement risk." This risk helps explain several empirical patterns, including the existence of the growth-value factor in returns, the value premium, and the high equity premium. We assess the magnitude of displacement risk using estimates of inter-cohort consumption differences across households and find support for the model. (c) 2012 Elsevier B.V. All rights reserved.
\end{abstract}

\section{Introduction}

In this paper we explore asset-pricing implications of innovation. We concentrate on two effects of innovation. First, while innovation expands the productive capacity of the economy, it increases competitive pressure on existing firms and workers, reducing profits of existing firms and eroding the human capital of older workers. Thus, innovation creates a risk factor, which we call the "displacement risk factor." Second, since economic rents from innovation are captured largely by the future cohorts of inventors through the firms they create, existing agents cannot use financial markets to avoid the negative effects of displacement. Innovation risks cannot be perfectly

\footnotetext{
This paper was previously circulated under the title "Demographics of Innovation and Asset Returns." We are grateful for comments and suggestions from Andy Abel, Frederico Belo, Jonathan Berk, George Constantinides, Adlai Fisher, John Heaton, Debbie Lucas, Toby Moskowitz, Marcus Opp, Tano Santos, Nick Souleles, Chris Telmer, Moto Yogo, and seminar participants at the Atlanta Fed, Australian National University, Bond University, Boston University, Chicago Booth, Frontiers of Finance 2008, Georgetown University, Georgia State University, UC Berkeley Haas, Imperial College, INSEAD, the Jackson Hole Finance Group, London Business School, London School of Economics, Minnesota Macro-Finance 2009, MIT Sloan, NBER AP Meetings, Paris School of Economics, SED 2009, SITE 2009, Stanford GSB, HEC Lausanne, University of Melbourne, University of New South Wales, University of Queensland, University of St. Gallen, University of Technology Sidney, UT Austin, Utah Winter Finance Conference 2011, WFA 2009, and Wharton.

* Corresponding author at: Haas School of Business, UC Berkeley, 545 Student Services Building, Berkeley, CA 94720-1900, USA. Tel.: + 1510 642 3421.

E-mail addresses: garleanu@haas.berkeley.edu (N. Gârleanu), lkogan@mit.edu (L. Kogan), spanagea@chicagobooth.edu (S. Panageas).

Tel.: +16172532289.

2 Tel.: +1 7738344711
} 
shared even if a complete menu of state-contingent claims is available for trading, since the future innovators, who are yet to enter the economy, are not able to trade with the current population of agents.

We capture the displacement effect in an overlappinggenerations general-equilibrium economy. We model production with multiple intermediate goods that are used to produce a single consumption good. Innovation creates a stochastically expanding variety of intermediate goods. Intermediate goods are partial substitutes; therefore, growth in their variety intensifies competition between their producers and leads to displacement of the established firms by the new entrants. In addition, older workers are not as well adapted to the new technologies as the new cohorts of agents, which implies that innovation diminishes older workers' human capital. Thus, there are two sides to innovation. The bright side is the increased productivity it brings, which raises aggregate output, consumption, and wages. The dark side is the reduced wage-bill and consumption shares of the older agents.

The displacement risk faced by older agents is a systematic risk factor, and distinct from aggregate-consumption risk. Individual Euler equations in our model cannot be aggregated into a pricing model based solely on aggregate consumption because of the wedge between the future consumption of all agents present currently and the future aggregate consumption: the latter includes the consumption of future cohorts, but the former does not. This wedge is stochastic and driven by innovation shocks. Thus, the standard aggregate-consumption-based pricing model must be augmented with the displacement risk factor. This argument helps explain several important empirical patterns in asset returns.

First, the displacement risk factor is connected to cross-sectional differences in stock returns. We assume that existing firms participate in innovation, but some firms are more likely to innovate than others. The more innovative firms derive a larger fraction of their value from future inventions and earn higher valuation ratios, which makes them "growth firms." Because of their relatively high exposure to the innovation shocks, growth firms offer a hedge against displacement risk and, in equilibrium, earn lower average returns than less innovative "value firms." Thus, heterogeneous exposure to displacement risk helps explain the positive average return premium earned by value stocks relative to growth stocks, called the value premium. Moreover, innovation shocks generate co-movement among value stocks and among growth stocks, giving rise to a value-growth factor in stock returns. Hence, our model rationalizes the empirical success of a multifactor model featuring a value-growth factor, documented by Fama and French (1993).

Second, the aggregate equity premium in our model is boosted by the stock-market exposure to the displacement risk factor. Large innovation shocks simultaneously lower the value of existing firms through increased competition and reduce consumption of existing agents through the erosion of their human and financial wealths. As a result, agents require a higher premium to hold stocks than could be inferred from the aggregate consumption series using standard pricing models.

Third, the equilibrium interest rate in our model is lower than suggested by the aggregate consumption process and agents' preferences. This is because individual agents' consumption growth is lower, on average, and riskier than that of aggregate consumption. This property of overlapping-generation economies is noted in the seminal paper of Blanchard (1985) and emphasized recently in an asset-pricing context by Gârleanu and Panageas (2007). Allowing for some degree of "catching up with the Joneses," as in Abel (1990), magnifies the size of this effect.

Our model also has implications for the cointegration properties of (a) the dividends paid by all corporations that current agents can trade and (b) the dividends paid by all firms at any point in time $t$, which we refer to as "aggregate" dividends. The latter are cointegrated with (in fact, a constant fraction of) aggregate consumption. However, the former are not, since the future share of aggregate output accruing to the firms existing currently declines towards zero asymptotically due to innovation. The lack of cointegration is empirically realistic and has been recently recognized in the literature as quantitatively important for understanding aggregate market returns.

We test the implications of our model empirically. We identify innovation shocks through their effect on the consumption of individual cohorts and show that intergenerational differences in consumption correlate with the return differences between value and growth stocks. In addition to the empirical tests, we use the empirical moments to calibrate our model and verify that its mechanism can reproduce key asset-pricing patterns quantitatively.

Our paper relates to several strands of the literature. A number of papers use an overlapping-generations framework to study asset-pricing phenomena, e.g., Abel (2003), Constantinides, Donaldson, and Mehra (2002), Geanakoplos, Magill, and Quinzii (2004), DeMarzo, Kaniel, and Kremer (2004, 2008), Gârleanu and Panageas (2007), Gomes and Michaelides (2008), or Storesletten, Telmer, and Yaron (2007). None of these papers, however, considers the displacement risk, which lies at the core of all our results. Our model of innovation is similar to Romer (1990), who studies endogenous sources of growth in a deterministic setting. We treat growth as exogenous and instead focus on the impact of stochastic innovation on financial-asset returns. Consistent with the premise of our model, Hobijn and Jovanovic (2001) show the permanent negative impact of innovation on incumbent firms in the context of the information-technology (IT) revolution. However, they employ a representative-agent framework and hence do not consider the displacement risk of innovation across agents.

Our paper also contributes to the theoretical literature on cross-sectional patterns in stock returns, which includes Berk, Green, and Naik (1999), Gala (2005), Gomes, Kogan, and Zhang (2003), Carlson, Fisher, and Giammarino (2004), Papanikolaou (2007), and Zhang (2005), among many. Our contribution is the new 
approach to the value-premium puzzle. Many of the earlier papers (e.g., Berk, Green, and Naik, 1999; Zhang, 2005) use partial or industry equilibrium settings with exogenous pricing of risk. Existing general equilibrium models (e.g., Gomes, Kogan, and Zhang, 2003) satisfy the aggregate-consumption capital asset pricing model (CCAPM) and thus do not address the challenge of reconciling the value premium with the standard CCAPM empirically. In contrast, we propose a novel source of systematic risk that accounts for return differences between value and growth stocks. Our model implies that the standard CCAPM fails to capture this risk factor.

We also contribute to the vast literature on the equitypremium puzzle (e.g., Mehra and Prescott, 1985; Campbell and Cochrane, 1999). The displacement risk factor helps reconcile a high equity premium with a smooth time series of aggregate consumption.

Finally, we relate to the empirical literature that studies departures from perfect consumption insurance between cohorts (e.g., Abel and Kotlikoff, 2001; Attanasio and Davis, 1996). Papers in that literature do not address the implications of such departures for asset pricing, as we do.

The rest of the paper is organized as follows. In Section 2 we formulate and in Section 3 we solve our model. Section 4 analyzes qualitative properties of the model, and Section 5 contains a quantitative evaluation, including empirical tests. Section 6 concludes. We collect technical results and proofs in Appendix A. To save space, we present a number of model extensions and additional results in an extended appendix, available online.

\section{Model}

\subsection{Agents' preferences and demographics}

We consider a model with discrete and infinite time: $t \in\{\ldots, 0,1,2, \ldots\}$. The size of the population is normalized to one. At each date a mass $\lambda$ of agents, chosen randomly, die, and a mass $\lambda$ of agents are born, so that the population remains constant. An agent born at time $s$ has preferences of the form

$\mathrm{E}_{s} \sum_{t=s}^{s+\tau} \beta^{(t-s)} \frac{\left(c_{t, s}^{\psi}\left(\frac{c_{t, s}}{C_{t}}\right)^{1-\psi}\right)^{1-\gamma}}{1-\gamma}$,

where $\tau$ is the (geometrically distributed) time of death, $c_{t, s}$ is the agent's consumption at time $t, C_{t}$ is aggregate consumption at time $t, \beta \in(0,1)$ is a subjective discount factor, $\gamma>0$ is the agent's relative risk aversion, and $\psi \in$ $[0,1]$ is a constant. Preferences of the form (1) were originally proposed by Abel (1990), and are commonly referred to as "keeping-up-with-the-Joneses" preferences. When $\psi=1$, these preferences specialize to the standard constant-relative-risk-aversion (CRRA) preferences. In general, for $\psi \in[0,1]$, agents place a weight $\psi$ on their own consumption (irrespective of what others are consuming) and a weight $1-\psi$ on their consumption relative to average consumption in the population. Our qualitative results hold independently of the keeping-up-with-the-
Joneses feature, which only helps at the calibration stage, by reducing the value of the interest rate.

A standard argument allows us to integrate over the distribution of the stochastic times of death and re-write preferences of the form (1) as

$\mathrm{E}_{s} \sum_{t=s}^{\infty}[(1-\lambda) \beta]^{(t-s)} \frac{\left(c_{t, s}^{\psi}\left(\frac{c_{t, s}}{C_{t}}\right)^{1-\psi}\right)^{1-\gamma}}{1-\gamma}$.

\subsection{Technology}

\subsubsection{Final-good firms}

There is a representative (competitive) final-good producing firm that produces the single final good using two categories of inputs: (a) labor and (b) a continuum of intermediate goods. Letting $L_{t}^{F}$ denote the efficiency units of labor that enter into the production of the final good, $A_{t}$ the number of intermediate goods available at time $t$, and $x_{j, t}$ the quantity of intermediate good $j$ used in the production of the final good, the production function of the final-good producing firm is

$Y_{t}=Z_{t}\left(L_{t}^{F}\right)^{1-\alpha}\left[\int_{0}^{A_{t}} \omega_{j, t}\left(x_{j, t}\right)^{\alpha} d j\right]$.

In this equation, $Z_{t}$ is a stochastic productivity process, which follows a random walk (in logs) with drift $\mu$ and volatility $\sigma_{\varepsilon}$ :

$\log \left(Z_{t+1}\right)=\log \left(Z_{t}\right)+\mu+\varepsilon_{t+1}, \quad \varepsilon_{t+1} \sim \mathrm{N}\left(0, \sigma_{\varepsilon}^{2}\right)$.

The constant $\alpha \in[0,1]$ in Eq. (3) controls the relative weight of labor and intermediate goods in the production of the final good, while $\omega_{j, t}$ captures the relative importance placed on the various intermediate goods. We specify $\omega_{j, t}$ as

$\omega_{j, t}=\left(\frac{j}{A_{t}}\right)^{\chi(1-\alpha)}, \quad \chi \geq 0$.

For $\chi=0$, the production function ( 3 ) is identical to the one introduced by the seminal Romer (1990) paper in the context of endogenous growth theory. Our version is slightly more general, since the factor weights $\omega_{j, t}$, which are increasing functions of the intermediate good index $j$, allow the production function to exhibit a "preference" for more recent intermediate goods. As we show below, this feature confers an additional degree of control over the individual-firm profit variability, which is helpful for calibration purposes.

Even though our aim here is not to explain the sources of growth in the economy, the production function (3) is useful for our purposes for several reasons: (a) innovation, i.e., an increase in the variety of intermediate goods $\left(A_{t}\right)$ helps increase aggregate output; (b) there is rivalry between existing and newly arriving intermediate goods, in the sense that increases in $A_{t}$ strengthen the competition among intermediate-good producers, and (c) heterogeneity in intermediate, rather than final, goods is technically convenient, since we can keep one unit of the final good as numeraire throughout. An exact 
illustration of the first two properties is provided in the next section, where we solve the model.

At each point in time $t$, the representative final-good firm chooses $L_{t}^{F}$ and $x_{j, t}$ (for $j \in\left[0, A_{t}\right]$ ) so as to maximize its profits:

$\pi_{t}^{F}=\max _{L_{t}^{F}, x_{j, t}}\left\{Y_{t}-\int_{0}^{A_{t}} p_{j, t} x_{j, t} d j-w_{t} L_{t}^{F}\right\}$,

where $p_{j, t}$ is the price of intermediate good $j$ and $w_{t}$ is the prevailing wage (per efficiency unit of labor).

\subsubsection{Intermediate-good firms}

The intermediate goods $x_{j, t}$ are produced by monopolistically competitive firms that own nonperishable blueprints to the production of these goods. Each intermediate good is produced by a single firm, while a single firm may produce a measure-zero set of intermediate goods. We assume that the production of the intermediate good $j \in\left[0, A_{t}\right]$ requires one unit of labor (measured in efficiency units) per unit of intermediate good produced, so that the total number of efficiency units of labor used in the intermediate-goods sector is

$L_{t}^{I}=\int_{0}^{A_{t}} x_{j, t} d j$.

The price $p_{j, t}$ of intermediate good $j$ maximizes the profits of the intermediate-good producer, taking the demand function of the representative final-good firm $x_{j}\left(p_{j, t} ; p_{j^{\prime} \neq j, t}, w_{t}\right) \equiv \arg \max _{x_{j, t}} \pi_{t}^{F}$ as given. To simplify notation, we shall write $x_{j, t}\left(p_{j, t}\right)$ instead of $x_{j, t}\left(p_{j, t} ; p_{j^{\prime} \neq j, t}, w_{t}\right)$. Production of the intermediate good $j$ generates profits

$\pi_{t}^{I}(j)=\max _{p_{j, t}}\left\{\left(p_{j, t}-w_{t}\right) x_{j, t}\left(p_{j, t}\right)\right\}$.

Any firm produces a zero-measure set of intermediate goods. Hence, there are no feedback effects of the pricing of any subset of intermediate goods it produces on the demand for any other intermediate goods. Therefore, the firm maximizes its profits from each intermediate good separately.

\subsection{Arrival of new intermediate goods and new agents}

\subsubsection{New products}

The number of intermediate goods $A_{t}$ expands over time as a result of innovations. Given our focus on asset pricing, we assume that the innovation process is exogenous for simplicity. The number of intermediate goods in our economy follows a random walk (in logs):

$\log \left(A_{t+1}\right)=\log \left(A_{t}\right)+u_{t+1}$.

We choose a random-walk specification in order to ensure that aggregate consumption is a random walk. The assumption of a random walk implies that-for a given $u_{t+1}$-the increase in production is proportional to the current level of production. This assumption is routinely used in the literature and is sometimes referred to as "standing on the shoulders of giants." See, e.g., Jones (1997).

We assume a single aggregate innovation shock for simplicity. As we show in the (online) extended appendix
(Section 2), our analysis extends to a multisector economy with correlated sectoral innovation shocks. The increment $u_{t+1}$ is i.i.d. across time for simplicity. To ensure its positivity, we assume that $u_{t+1}$ is Gamma distributed with shape parameter $k$ and scale parameter $v$ (the gamma probability density function $f(x)$ is proportional to $\left.x^{k-1} e^{-x / v}\right)$.

The intellectual property rights for the production of the $\Delta A_{t+1} \equiv A_{t+1}-A_{t}$ new intermediate goods belong either to arriving agents or to existing firms. We assume that a fraction $\kappa \in[0,1]$ of the total value of the new blueprints is allocated to arriving entrepreneurs, while the complementary fraction $1-\kappa$ is introduced by established firms and hence belongs indirectly to existing agents, who own these firms.

While we assume that the arrival of new innovation and the allocation of the proceeds from innovation are exogenous, we note that we could extend the model to obtain similar allocations in a world with endogeneous innovation. In such an extension, $A_{t}$ would play the role of a shock to the innovation sector. Additionally, we would need appropriate assumptions on the relative productivity of different groups of innovators, so as to obtain the same allocation of the proceeds from innovation that we assume here. Given the asset-pricing focus of the paper, such an extension would add complexity without altering the intuitions or the results, and, therefore, we omit it.

\subsubsection{Workers}

New agents are of two types and differ according to their endowments: Entrepreneurs account for a fraction $\phi \in(0,1)$ of new agents and arrive in life with ideas for new firms. We discuss them in the next subsection. In this subsection we focus on workers, who make up a fraction $1-\phi$ of new agents. Workers start life with a constant endowment of $\bar{h}$ hours per period, which they supply inelastically. The ratio of efficiency units of labor to hours is affected by two factors: (a) age and experience, and (b) skill obsolescence. To capture the first notion, we assume that the ratio of labor efficiency units to hours changes geometrically with age at the rate $\delta$, so that in the absence of skill obsolescence, the ratio of a worker's endowment of efficiency units at time $t$ to the respective endowment at the time of birth $s \leq t$ is given by $(1+\delta)^{t-s}$.

To motivate the second notion (skill obsolescence), we note that in the real world younger workers are likely to be more productive in the presence of increased technological complexity than older workers. One potential reason is that younger workers' education gives them the appropriate skills for understanding the technological frontier. By contrast, older workers are likely to be challenged by technological advancements. In the extended online appendix (Section 1) we present a simple vintage model of the labor market that introduces imperfect substitution across labor supplied by agents born at different times. To expedite the presentation of the main results, in this section we assume that labor is a homogeneous good and that workers' endowment of efficiency units depreciates in a way that replicates the outcome of the more elaborate vintage model. 
Specifically, we assume that a worker's total supply of efficiency units of labor is given by $\bar{h}(1+\delta)^{t-s} q_{t, s}$ with

$\log \left(q_{t+1, s}\right)=\log \left(q_{t, s}\right)-\rho u_{t+1}$

and $\rho \geq 0$. This specification captures the idea that advancements of the technological frontier act as depreciation shocks to the productivity of old workers. Such shocks generate cohort effects in individual consumption and income, which are present in historical data, as we show in Section 5.1. We normalize the initial endowment of efficiency units so that the aggregate number of efficiency units in the economy is constant. In particular, we set

$q_{s, s}=1-(1-\lambda)(1+\delta) e^{-\rho u_{s}}$

and $\bar{h}=1 / \lambda$. We assume that $(1-\lambda)(1+\delta) \leq 1$. Note that, with $z=(1-\lambda)(1+\delta)$, our assumptions imply

$$
\begin{aligned}
\frac{L_{t}}{(1-\phi)} & =\lambda \bar{h} \sum_{s \leq t} z^{t-s} q_{t, s} \\
& =\sum_{s \leq t} z^{t-s}\left(1-z e^{-\rho u_{s}}\right) e^{-\rho \sum_{v=s+1}^{t} u_{v}} \\
& =\sum_{s \leq t} z^{t-s} e^{-\rho \sum_{v=s+1}^{t} u_{v}}-z^{t-s+1} e^{-\rho \sum_{v=s}^{t} u_{v}}=1 .
\end{aligned}
$$

As a result, the number of per-worker efficiency units, $L_{t} /(1-\phi)$ with $L_{t}=L_{t}^{F}+L_{t}^{I}$, is always equal to one, and, hence, $\bar{h}(1+\delta)^{t-s} q_{t, s} \lambda(1-\lambda)^{t-s}$ can be interpreted as the fraction of total wages that accrues to workers born at time $s$.

We note in passing that, in the interest of parsimony, the baseline model assumes no intra-cohort heterogeneity among workers, such as labor-income heterogeneity due to educational choice at the time of birth. In the extended appendix (Section 8), we extend the model to allow for education level choice at birth. This assumption gives rise to a skill premium in income. The skill premium is higher within cohorts that enter the workforce at times of rapid technological advancement (as captured by the shock $u_{s}$ ), which is consistent with the evidence in Attanasio and Davis (1996). The analysis of the interaction between technology and the skill premium can be found in a number of recent papers, e.g., Krusell, Ohanian, RíosRull, and Violante (2000).

\subsubsection{Entrepreneurs and new value and growth firms}

Entrepreneurs arrive endowed with ideas for new blueprints. They start a continuum of firms that produce the respective intermediate goods, and introduce them into the stock market.

We assume that new firms are heterogeneous in their access to new blueprints in future periods. How new blueprints are distributed among firms in future periods is only relevant for the cross-section of stock returns and has no effect on aggregate prices and quantities. Thus, our model affords considerable flexibility in modeling the cross-section of stock returns and firm dynamics. For ease of exposition, we make a stylized assumption: some firms can receive blueprints in future periods, while the remainder of the firms cannot. We refer to the first type of firms as "growth" firms, and the latter type as "value" firms. Thus defined, growth firms in the model trade at higher prices relative to their current earnings than value firms, which mirrors the empirical definitions of growth and value firms. As we show in Section 5.2, our model can generate realistic cross-sectional dispersion in valuation ratios and expected returns among growth and value firms. The cost of our stylized assumption on blueprint allocation is that the transition dynamics of firms between value and growth portfolios is too simplistic compared to the documented empirical patterns. This limitation in our treatment of firm dynamics is not critical for the main point of the paper and would be relatively easy to overcome by specifying a richer, stochastic blueprint allocation schedule for all firms.

Value firms created at time $t$ are only entitled to a fraction $\eta \kappa$ of the value of blueprints introduced in that period, where $\eta \in(0,1]$. By contrast, new "growth" firms are entitled to a fraction $(1-\eta) \kappa$ of the value of new blueprints at time $t$, but they also receive a fraction of the new blueprints in future periods. Specifically, in period $t$, growth firms born at $s \in(-\infty, t-1]$ obtain a fraction

$(1-\kappa)\left(\frac{1-\varpi}{\varpi}\right) \varpi^{t-s}$

of the value of the $\Delta A_{t}$ new blueprints. Fig. 1 illustrates the blueprint allocation. One can easily relax these stylized assumptions on the distribution of new blueprints (say, by introducing firm-specific shocks) so as to obtain the desired cross-sectional distribution and dynamics of firm characteristics. ${ }^{3}$

To simplify matters, we assume that there are no intracohort differences among growth firms and any two growth firms of the same cohort obtain the same value of blueprints in any given period. The geometric decay in the fraction of new blueprints that accrues to a given growth firm as a function of its age ensures that, asymptotically, the total market capitalization of firms existing at any given, fixed time $t$ goes to zero as a fraction of the aggregate market capitalization as time progresses. It also implies that today's growth firms become asymptotically value firms.

Fama and French (1995) document that growth firms exhibit (i) higher rates of book value growth; (ii) higher profitability; and (iii) higher growth rates of earnings, relative to value firms. ${ }^{4}$ Despite the simplified distinction between the value and growth firms, our model is consistent with the fact that growth firms exhibit higher earnings growth than value firms. In our model this pattern is a direct consequence of the fact that growth firms keep receiving blueprints after their creation, whereas value firms do not. Furthermore, the average growth firm generates higher profits per blueprint that it owns than the average value firm, since growth firms own newer vintages of blueprints than value firms and more

\footnotetext{
${ }^{3}$ Luttmer (2007), for instance, presents an interesting approach to explaining the size distribution of firms in a model that shares some features with Romer (1990). Even though the size distribution does not matter for the insights that we develop in this paper, the methods of Luttmer (2007) could potentially be used with the present model to account for the empirical firm size distribution.

${ }^{4}$ For a recent contribution, see also Imrohoroglu and Tuzel (2011).
} 
Fractions of new blueprint value accruing to:

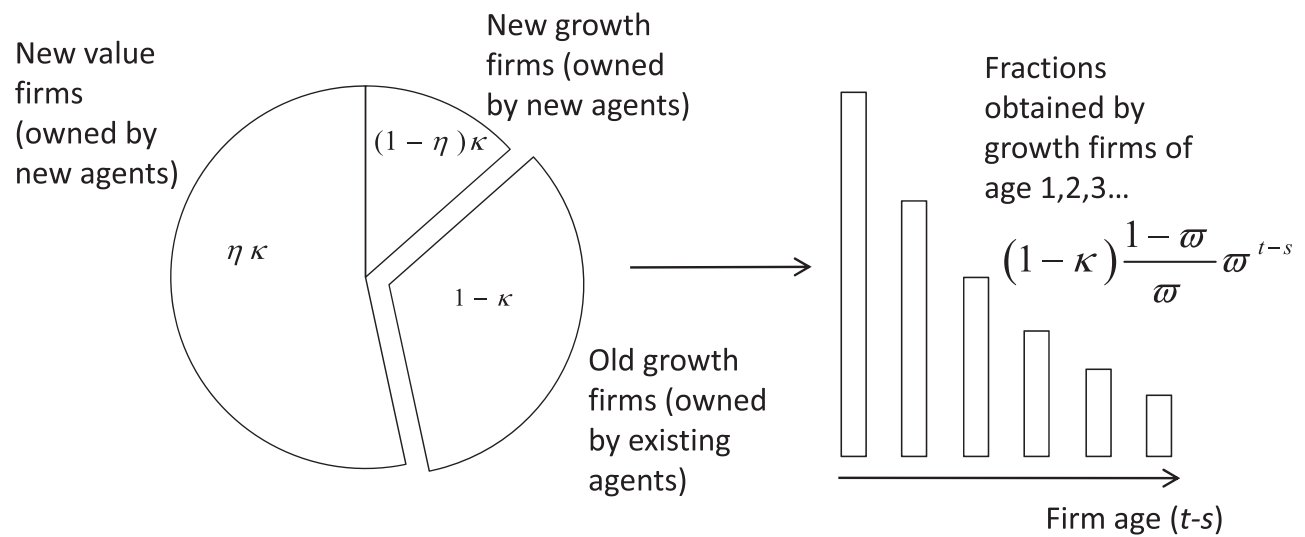

Fig. 1. Illustration of the allocation of new blueprint value.

recent blueprints are more productive, given the production function (3), (5). ${ }^{5}$

\subsection{Asset markets}

There exists a complete set of state-contingent claims. At each point in time, existing agents can trade in zero net supply Arrow-Debreu securities contingent on the joint realization of future shocks $\varepsilon_{t+\tau}$ and $u_{t+\tau}, \forall \tau>0$. We denote the corresponding stochastic discount factor by $\xi_{t}$, so that the time-s value of a claim paying $D_{t}$ at time $t$ is given by $\mathrm{E}_{s}\left(\xi_{t} / \xi_{s}\right) D_{t}$.

In addition, agents have access to annuity markets as in Blanchard (1985). (We refer the reader to that paper for details.) The joint assumptions of perfect spanning and frictionless annuity markets simplifies the analysis considerably, since feasible consumption choices are constrained by a single intertemporal budget constraint. For a worker, that intertemporal budget constraint is given by

$\mathrm{E}_{s} \sum_{t=s}^{\infty}(1-\lambda)^{t-s}\left(\frac{\xi_{t}}{\xi_{s}}\right) c_{t, s}^{w}=\mathrm{E}_{s} \sum_{t=s}^{\infty}(1-\lambda)^{t-s}\left(\frac{\xi_{t}}{\xi_{s}}\right) w_{t} q_{t, s} \bar{h}(1+\delta)^{t-s}$,

where $c_{t, s}^{w}$ denotes the time- $t$ consumption of a representative worker who was born at time $s$. The left-hand side of (14) represents the present value of a worker's consumption, while the right-hand side represents the present value of her income. Similarly, letting $c_{t, s}^{e}$ denote the time- $t$ consumption of a representative inventor who was born at time $s$, her intertemporal budget constraint is

$\mathrm{E}_{s} \sum_{t=s}^{\infty}(1-\lambda)^{t-s}\left(\frac{\xi_{t}}{\xi_{s}}\right) c_{t, s}^{e}=\frac{1}{\lambda \phi} V_{s, s}$

\footnotetext{
${ }^{5}$ To see this more clearly, note that, conditional on a firm's age, a growth firm has blueprints not only corresponding to the time of its creation, but also corresponding to more recent times. Hence, conditional on age, a growth firm exhibits higher profits per blueprint than a value firm. Since this higher profitability of growth firms holds conditional on age, it also holds unconditionally, i.e., if one averages across age groups.
}

where $V_{s, s}$ is the time-s total market capitalization of new firms created at time $s$, and, therefore, the right-hand side represents the wealth at birth of a representative inventor. In order to determine the total market value of firms created at time $s$, let $\Pi_{j, s}^{I}$ be the present value of profits from the production of intermediate good $j$ :

$\Pi_{j, s}^{I}=\left[\mathrm{E}_{s} \sum_{t=s}^{\infty}\left(\frac{\xi_{t}}{\xi_{s}}\right) \pi_{j, t}^{I}\right]$.

The total market capitalization of all new firms can then be written as

$$
\begin{aligned}
V_{s, s}= & \kappa \int_{A_{s-1}}^{A_{s}} \Pi_{j, s}^{I} d j+(1-\varpi) \\
& \times \mathrm{E}_{s} \sum_{t=s+1}^{\infty}\left(\frac{\xi_{t}}{\xi_{s}}\right)(1-\kappa) \varpi^{t-s-1} \int_{A_{t-1}}^{A_{t}} \Pi_{j, s}^{I} d j .
\end{aligned}
$$

The first term in Eq. (17) is the value of the blueprints for the production of new intermediate goods that are introduced by new firms (both "growth" and "value" firms) at time $s$. The second term captures the value of "growth opportunities," that is, the value of blueprints to be received in future periods $t>s$ by growth firms created at time $s$.

\subsection{Equilibrium}

The definition of equilibrium is standard. To simplify notation, we let $\phi^{e}$ and $\phi^{w}$ denote the fractions of entrepreneurs and workers in the population, respectively.

Definition 1. An equilibrium is a collection of adapted stochastic processes $\left\{x_{j, t}, L_{t}^{F}, c_{t, s}^{w}, c_{t, s}^{e}, \xi_{t}, p_{j, t}, w_{t}\right\}$ with $j \in$ $\left[0, A_{t}\right]$ and $t \geq s$ such that

1. (Consumer optimality) Given $\xi_{t}$, the process $c_{t, s}^{w}$ (respectively, $c_{t, s}^{e}$ ) solves the optimization problem (2) subject to the constraint (14) (respectively, constraint (15)).

2. (Profit maximization) The prices $p_{j, t}$, solve the optimization problem (8) given $L_{t}^{F}, x_{j^{\prime} \neq j, t}$, and $w_{t}$, and $L_{t}^{F}$ and $x_{j, t}$ solve the optimization problem (6) given $p_{j, t}$ and $w_{t}$. 
3. (Market clearing) Labor and goods markets clear

$$
\begin{aligned}
& L_{t}^{F}+L_{t}^{I}=(1-\phi), \\
& \lambda \sum_{s=-\infty}^{t} \sum_{i \in\{w, e\}}(1-\lambda)^{t-s} \phi^{i} c_{t, s}^{i}=Y_{t} .
\end{aligned}
$$

\section{Solution}

\subsection{Equilibrium output, profit, and wages}

Proposition 1 provides a closed-form expression for output, profits, and wage payments.

Proposition 1. In equilibrium, aggregate output is given by

$Y_{t}=\frac{\left(\alpha^{2}\right)^{\alpha}\left(\frac{1-\alpha}{1+\chi}\right)^{1-\alpha}}{\alpha^{2}+1-\alpha}(1-\phi) Z_{t} A_{t}^{1-\alpha}$.

The profit of the representative final-good firm is $\pi_{t}^{F}=0$. The profits from the production of intermediate good $x_{j, t}$ are positive and given by

$\pi_{j, t}^{I}=(1+\chi)\left(\frac{j}{A_{t}}\right)^{\chi} \frac{Y_{t}}{A_{t}} \alpha(1-\alpha)$.

Finally, aggregate profits are given by $\int_{0}^{A_{t}} \pi_{j, t}^{I} d j=\alpha(1-\alpha) Y_{t}$, while aggregate wage payments equal $\left(\alpha^{2}+1-\alpha\right) Y_{t}$.

Proposition 1 establishes two important results. First, the number of intermediate inputs $\left(A_{t}\right)$ in Eq. (20) is raised to the power $1-\alpha$. This means that aggregate output is increasing in the number of intermediate inputs. However, the sensitivity of output to the number of inputs depends on the elasticity of substitution between different varieties of intermediate goods. For instance, as $\alpha$ approaches one, intermediate goods become perfect substitutes, and a larger variety of intermediate goods leads to more competition among firms and lower profits for existing intermediate-good producers without changing the overall productive capacity of the economy.

Second, the time series of profits $\pi_{j, t}^{I}$ from the production of a given intermediate good $j$ is not cointegrated with aggregate output $Y_{t}$. The reason is that the variety of intermediate goods $A_{t}$ grows over time and, hence, $\pi_{j, t}^{I} / Y_{t} \rightarrow 0$ as $t \rightarrow \infty$. As a result, dividends of an individual firm are not cointegrated with aggregate output, which is intuitive because of the constant arrival of competing firms. In comparison, aggregate profits are a constant fraction $\alpha(1-\alpha)$ of total output.

A limitation of the model is that the reduction of the incumbent firms' profits is driven by reductions in the quantities of intermediate goods produced by incumbent firms, rather than the relative prices that they charge. This feature of the model follows from the simple monopolistic-competition structure of the model, which implies that all goods (irrespective of the time since their introduction) are priced according to the constant-markup rule $p_{j, t}^{I}=w_{t} / \alpha$. In reality, both price and quantity reductions lead to a fall of incumbent firms' profits (e.g., Gort and Klepper, 1982; Klepper and Graddy, 1990; Jovanovic and MacDonald, 1994). For our purposes and conclusions, all that matters is that total profits decline in units of the numeraire (final good), be it through quantity or price effects. Accordingly, for our baseline specification, we use the tractable structure of the Romer (1990) model. We discuss possible extensions of the baseline model that generate declines in relative prices of older intermediategood vintages in the extended appendix (Section 6).

\subsection{The stochastic discount factor}

To determine the stochastic discount factor $\xi_{t}$, we recall that, since agents have access to a full set of statecontingent securities after their birth, a consumer's lifetime consumption profile can be obtained by maximizing (2) subject to a single intertemporal budget constraint (constraint (14) if the agent is a worker and constraint (15) if the agent is an inventor). Attaching a Lagrange multiplier to the intertemporal budget constraint, maximizing with respect to $c_{t, s}^{i}$, and relating the consumption at time $t$ to the consumption at time $s$ for a consumer born at $s$ gives

$c_{t, s}^{i}=c_{s, s}^{i}\left(\frac{C_{t}^{(1-\psi)(1-\gamma)}}{C_{s}^{(1-\psi)(1-\gamma)}} \beta^{-(t-s)} \frac{\xi_{t}}{\xi_{s}}\right)^{-1 / \gamma} \quad$ for $i \in\{e, w\}$.

From this equation, the aggregate consumption at any point in time is

$$
C_{t}=\lambda \sum_{s=-\infty}^{t} \sum_{i \in\{w, e\}}(1-\lambda)^{t-s} \phi^{i} c_{s, s}^{i}\left(\frac{C_{t}^{(1-\psi)(1-\gamma)}}{C_{s}^{(1-\psi)(1-\gamma)}} \beta^{-(t-s)} \frac{\xi_{t}}{\xi_{s}}\right)^{-1 / \gamma}
$$

Expressing $C_{t+1}$ in the same way and then using (23) gives

$$
C_{t+1}=(1-\lambda) C_{t}\left(\beta^{-1} \frac{C_{t+1}^{(1-\psi)(1-\gamma)}}{C_{t}^{(1-\psi)(1-\gamma)}} \frac{\xi_{t+1}}{\xi_{t}}\right)^{-1 / \gamma}+\lambda \sum_{i \in\{w, e\}} \phi^{i} c_{t+1, t+1}^{i} .
$$

Dividing both sides of (24) by $C_{t}$, solving for $\xi_{t+1} / \xi_{t}$, and noting that $C_{t}=Y_{t}$ in equilibrium leads to

$$
\frac{\xi_{t+1}}{\xi_{t}}=\beta\left(\frac{Y_{t+1}}{Y_{t}}\right)^{-1+\psi(1-\gamma)}\left[\frac{1}{1-\lambda}\left(1-\lambda \sum_{i \in\{w, e\}} \phi^{i} \frac{c_{t+1, t+1}^{i}}{Y_{t+1}}\right)\right]^{-\gamma} \text {. }
$$

To obtain an intuitive understanding of Eq. (25), it is easiest to focus on the case $\psi=1$, so that agents have standard CRRA preferences. In this case, the stochastic discount factor is the product of the subjective discount factor $\beta$ and two terms raised to the power $-\gamma$. The first term is $\left(Y_{t+1} / Y_{t}\right)$, and it captures aggregate consumption growth. The second term, namely $(1 /(1-\lambda))\left(1-\lambda \sum_{i \in\{w, e\}}\right.$ $\left.\phi^{i} c_{t+1, t+1}^{i} / Y_{t+1}\right)$, gives the proportion of output at time $t+1$ that accrues to agents already alive at time $t$. Note that only a proportion $1-\lambda$ of existing agents survive between $t$ and $t+1$, and that the arriving generation claims a proportion $\lambda \sum_{i \in\{w, e\}} \phi^{i} c_{t+1, t+1}^{i} / Y_{t+1}$ of aggregate output. The combination of these terms yields the consumption growth between $t$ and $t+1$ of the surviving agents. 
Eq. (25) states an intuitive point: since (ignoring consumption externalities) only agents alive at time $t$ are relevant for asset pricing, it is exclusively their consumption growth that determines the stochastic discount factor, not the aggregate consumption growth, which includes the consumption of agents born at time $t+1$.

The failure of the aggregate-consumption CAPM (CCAPM) in our model is distinct from earlier results obtained in incomplete-market economies (e.g., Constantinides and Duffie, 1996; Heaton and Lucas, 1996; Basak and Cuoco, 1998), where various frictions and constraints prevent perfect risk sharing among agents. Consistent with Grossman and Shiller (1982), Krueger and Lustig (2010) show that nontraded idiosyncratic income shocks by themselves may lead to imperfect risk sharing among existing agents, but may not invalidate the equity-premium implications of the CCAPM: they need to be interacted with frictions or portfolio constraints. Our model abstracts from such issues, so that the consumption of existing agents is perfectly correlated. Instead, the key economic mechanism is the failure of intergenerational risk sharing. This qualitative distinction is important for empirical work: to test our model, one should look for evidence of imperfect risk sharing among generations, rather than among existing agents. We undertake this task in Section 5.

To conclude the computation of equilibrium, we need to obtain an expression for the consumption shares $c_{t, t}^{i} / Y_{t}, i \in\{w, e\}$. This can be done by using the intertemporal budget constraints (15) and (14). Using the fact that the growth rates of consumption and output in our model are i.i.d. over time, we show (see Proposition 2 in Appendix A) that

$$
1-\lambda \sum_{i \in\{w, e\}} \phi^{i} \frac{c_{t+1, t+1}^{i}}{Y_{t+1}}=v\left(u_{t+1} ; \theta^{e}, \theta^{w}, \theta^{g}\right) \text {, }
$$

with

$$
\begin{gathered}
v\left(u_{t+1} ; \theta^{e}, \theta^{w}, \theta^{g}\right) \equiv 1-\theta^{e} \alpha(1-\alpha)\left(\kappa\left(1-e^{-(1+\chi) u_{t+1}}\right)+(1-\varpi) \theta^{g}\right) \\
-\theta^{w}\left(\alpha^{2}+1-\alpha\right)\left(1-(1-\lambda)(1+\delta) e^{-\rho u_{t+1}}\right)
\end{gathered}
$$

and constants $\theta^{e}, \theta^{w}$, and $\theta^{g}$ solving a system of three nonlinear equations in three unknowns. Given the interpretation of $1-v\left(u_{t+1} ; \theta^{e}, \theta^{w}, \theta^{g}\right)$ as the fraction of consumption that accrues to new agents, $(1-\lambda)^{-1} v\left(u_{t+1} ; \theta^{e}, \theta^{w}, \theta^{g}\right)$ captures the net adjustment applied to the aggregate consumption growth to obtain the consumption growth of existing agents. Accordingly, we refer to $(1-\lambda)^{-1} v\left(u_{t+1} ; \theta^{e}, \theta^{w}, \theta^{g}\right)$ as the displacement factor.

We conclude this subsection by noting that Eq. (25) is a robust implication of our analysis. It only relies on the assumption that existing agents can trade in a full set of state-contingent securities, so that their consumption is given by Eq. (22). Eq. (22) would still hold in several realistic but inessential extensions of the model that would allow for bequests and gifts across generations, government debt, intergenerational transfers mandated by the government, or adjustable and depreciable physical and human capital. Such extensions would not change the functional form of Eq. (25) and would only affect the magnitude of the displacement factor. For instance, in an economy populated by a representative, altruistically linked dynasty, bequests and gifts between the different generations would ensure that every living member of the dynasty enjoys the same consumption. Accordingly, arriving agents' consumption is equal to per capita output, and the displacement factor is identically equal to one. Our calibration of the model in Section 5 is robust to such extensions because it is based directly on the magnitude of the displacement factor in the data.

\section{Qualitative properties of the equilibrium}

To highlight the departure from the standard paradigm, we consider a limiting case of the model with no aggregate consumption risk. The limit of no aggregate risk is not meant to be a realistic description of market dynamics; instead, it helps clarify the intuition behind displacement risk by eliminating other sources of consumption variability.

Specifically, suppose that $\sigma=0$ and $\rho>0$, and let $\alpha$ approach 1 . Eq. (20) implies that the volatility of aggregate output, and of aggregate consumption, approaches zero. Then, according to the standard CCAPM, risk premiums must vanish in the limit. This is not the case in our model, as shown in Lemma 1.

Lemma 1. Assume that $\sigma=0, \rho>0, \kappa=1$, and

$1>\beta(1-\lambda)^{\gamma} e^{\mu \psi(1-\gamma)+(1 / 2) \sigma^{2} \psi^{2}(1-\gamma)^{2}}$,

$1 \leq \beta(1+\delta)^{-\gamma} e^{\mu \psi(1-\gamma)+(1 / 2) \sigma^{2} \psi^{2}(1-\gamma)^{2}} \mathrm{E}\left[e^{\rho \gamma u_{t+1}}\right]$.

Then, an equilibrium exists. Moreover, letting $R_{t}$ be the return of any stock,

$\lim _{\alpha \rightarrow 1} \operatorname{Var}\left(\Delta Y_{t+1}\right)=0$,

$\lim _{\alpha \rightarrow 1} \frac{\partial\left(\xi_{t+1} / \xi_{t}\right)}{\partial u_{t+1}}>0$,

$\lim _{\alpha \rightarrow 1}\left\{\mathrm{E}\left(R_{t}\right)-\left(1+r^{f}\right)\right\}>0$.

The intuition behind Lemma 1 is straightforward. While the volatility of aggregate consumption vanishes as $\alpha$ approaches one, the volatility of existing agents' consumption does not. As $\alpha$ approaches one, intermediate inputs behave more and more like perfect substitutes. This implies that innovations have a vanishing effect on aggregate output, their only impact being the redistribution from old to young firms and from old to young agents (since $\rho>0$ ). Thus, innovation shocks $\left(u_{t}\right)$ are systematic consumption shocks from the perspective of existing agents and affect the pricing kernel as stated by (30), but they are not aggregate shocks in the conventional sense. Since the profits of existing firms are exposed to the innovation shocks $\left(u_{t}\right)$, stock returns of existing companies are correlated with the consumption growth of existing agents and, therefore, command a risk premium. ${ }^{6}$

\footnotetext{
${ }^{6}$ A caveat behind Lemma 1 is that, in the limit $\alpha=1$, the profits of intermediate-good firms disappear. Hence, even though the rate of return on a stock is well defined in the limit (because rates of return
} 
Our model also generates a positive value premium without aggregate uncertainty. To see this, consider a claim on future aggregate dividends (we assume for the purpose of this illustration that such a claim has finite value), which include the dividends to be paid by the current firms and the dividends to be paid by future firms-i.e., dividends due to the exercise of growth opportunities. On the one hand, since aggregate output (and hence aggregate dividends) is deterministic, the claim on aggregate dividends returns the risk-free rate. On the other hand, this return is a weighted average of the return on current firms-i.e., the market return that Lemma 1 shows to be higher than the risk-free rate-and the return on growth opportunities. Thus, we conclude that there exists a positive spread between average returns on assets in place and growth opportunities, which leads to a positive value premium. Since there are no aggregate shocks, the value premium is driven by innovation risk.

The positive value premium in our model is due to the fact that assets in place and the value of growth opportunities have different exposures to the innovation shocks $u_{t}$. Specifically, the value of assets in place is negatively exposed to the innovation shock, while the value of growth opportunities has a positive exposure. According to Lemma 1 (Eq. (30)), innovation shocks command a positive price of risk, and, therefore, value stocks must earn a higher average rate of return than growth stocks. From the point of view of the agents, the claim on future growth opportunities embedded in growth stocks acts as a hedge against innovation shocks, driving down the expected return on growth stocks. Thus, the rationale behind the value premium in our model is quite different from the explanations proposed previously. A representative sample of papers using structural models to analyze the value premium includes Berk, Green, and Naik (1999), Gomes, Kogan, and Zhang (2003), Carlson, Fisher, and Giammarino (2004, 2006), and Zhang (2005). These models either take risk factors as exogenous and disconnected from economic fundamentals, or derive equilibrium pricing relationships consistent with the conditional CCAPM, in which case value stocks earn higher average returns because of their higher exposure to the aggregate consumption risk. In our model there exists a fundamental risk factor, distinct from aggregate consumption growth, that affects the return differential between value and growth stocks.

The next lemma establishes a general relationship between realizations of the displacement risk factor and stock returns.

\footnotetext{
(footnote continued)

are not affected by the levels of dividends and prices), the limiting case $\alpha=1$ is of limited practical relevance. However, it has theoretical interest because it illustrates in a simple way the asset-pricing implications of the wedge between aggregate consumption and existing agents' consumption. In particular, Lemma 1 shows the existence of a distinct displacement risk factor. This result holds more generally than the limiting case of $\alpha=1$ and illustrates why the CCAPM relationship may understate the risks associated with investing in stocks.
}

Lemma 2. Let $\Phi \equiv \Pi_{j, t}^{I} / \pi_{j, t}^{I}$, where $j$ is the index of any intermediate good in $\left[0, A_{t}\right]$, and $\Pi_{j, t}^{I}$ is given by (16). Define

$$
\begin{aligned}
& R_{t+1}^{a}=\left(\frac{\Phi}{\Phi-1}\right)\left(\frac{\pi_{j, t+1}^{I}}{\pi_{j, t}^{I}}\right), \quad \forall j \in\left[0, A_{t}\right], \\
& R_{t+1}^{o}=\left(\frac{Y_{t+1}}{Y_{t}}\right) \frac{(1-\kappa)\left(1-e^{-(1+\chi) u_{t+1}}\right)+\varpi \theta^{g}}{\theta^{g}} .
\end{aligned}
$$

Then, for any firm there exists $w_{t}^{o} \in[0,1]$ known at time $t$ such that the gross realized return $R_{t+1}$ on the firm can be expressed as a weighted average of $R_{t+1}^{a}$ and $R_{t+1}^{o}$ :

$R_{t+1}=\left(1-w_{t}^{o}\right) R_{t+1}^{a}+w_{t}^{o} R_{t+1}^{o}$.

Specifically, $w_{t}^{o}=0$ for value firms and $w_{t}^{o} \in(0,1)$ for growth firms. Furthermore,

$\frac{\partial R_{t+1}^{a}}{\partial u_{t+1}}<0, \quad \frac{\partial R_{t+1}^{o}}{\partial u_{t+1}}>0$.

Note that the ratio $\Phi$ in Lemma 2 does not depend on the index $j$, and, thus, all value firms have the same priceearnings ratio $(P / E)$, regardless of which intermediate goods they produce. Since the increments to the log stochastic discount factor and the increments to log profits of value firms are i.i.d. across time, $\Phi$ is a constant. We show this formally as part of the proof of Proposition 2.

Lemma 2, which holds for any set of parameters, decomposes the gross return on any stock as a weighted average of two basic returns, namely $R_{t+1}^{a}$ and $R_{t+1}^{o} \cdot R_{t+1}^{a}$ is the gross return on a value stock (assets in place), while $R_{t+1}^{o}$ can be interpreted as the gross return on a pure "growth opportunity," i.e., as the return on the component of a growth stock's market value that is associated with future rather than existing blueprints. The weight $w_{t, s}^{o}$ reflects the fraction of a stock's value that is due to growth opportunities. For instance, $w_{t, s}^{o}=0$ for a value stock, while $w_{t, s}^{o} \in(0,1)$ for a growth stock. Eqs. (32), (33), (20), and (21) imply that the difference $\log \left(R_{t+1}^{a}\right)-\log \left(R_{t+1}^{o}\right)$ is not affected by $\varepsilon_{t+1}$, while Eq. (35) shows that it is a declining function of $u_{t+1}$. In light of Eq. (34), the same properties hold true for the log-return differential between a portfolio of value stocks and a portfolio of growth stocks. This is because, according to Eq. (34), the return of a stock is also a weighted average of the two basic returns, $R_{t+1}^{a}$ and $R_{t+1}^{o}$. Thus, the log-return differential between value and growth stocks isolates realizations of the displacement factor, and can act as an empirical proxy, or a "mimicking portfolio," for the unobserved displacement factor. This property of our model is supported by the empirical success of asset pricing models featuring a multifactor specification, which includes a "value-minus-growth" return as one of the factors (see Fama and French, 1993).

It is useful to note that, because the agent is able to constantly rebalance her portfolio from one period to the next, she can create a factor-mimicking portfolio by simply combining positions in the value and growth firms "of the day." This feature of the model does not rely on our stylized modeling of value and growth firms. For instance, an agent can obtain her desired exposure to the realization of the displacement factor at time $t+1$ by 
constantly rebalancing her portfolio to include appropriate short or long positions in new growth stocks and value stocks.

We would also like to note that, in a multisector version of the baseline model with correlated innovation shocks, we can show that the value-minus-growth return is likely to be larger within sectors that experience innovation shocks rather than across sectors (this extension is contained in the extended online appendix (Section 2)). This result is consistent with the data and intuitive. The firms that are most negatively affected by new entrants are the entrants' immediate competitors inside the sector, rather than distant competitors in other sectors. Thus, market-value decline in response to a sector-specific innovation shock is strongest for assets in place in the same sector, while market-value appreciation is strongest for growth options in the same sector.

We conclude this section by discussing the relationship between the equilibrium stochastic discount factor in our model and the Sharpe-Lintner-Mossin CAPM. Without the consumption externality in preferences $(\psi=1)$, the CAPM relationship holds in our model with respect to the total wealth of existing agents, which includes both their stock holdings and their human capital. The reason is that the ratio of consumption to total wealth is constant in our model, and, hence, a reasoning similar to the one in Section 3.2 implies that when $\psi=1$, the stochastic discount factor can be expressed in terms of the growth rate of the total wealth of existing agents. Since the two components of total wealth (financial wealth and human capital) are not perfectly correlated inside the model, the stock market cannot be used as a proxy for total wealth. This well-known critique of the empirical implementations of the CAPM applies, at a theoretical level, within our model. More generally, when $\psi<1$, the stochastic discount factor is an exponential affine function of the aggregate consumption growth and the wealth growth of existing agents, and CAPM does not hold with respect to the latter.

\section{Quantitative evaluation}

In this section we examine the model's empirical implications and evaluate its quantitative performance. Specifically, Section 5.1 derives two main observable implications. We show that our theory predicts the presence of cohort effects in the cross-section of consumption data. Furthermore our model predicts that the permanent component of the time series of cohort effects should be positively correlated with the return on a growth-minus-value portfolio. We provide supporting statistical evidence for both of these assertions. In Section 5.2 we calibrate the model to approximately match several key empirical moments (especially the cohort-related moments), and evaluate its implications for asset-return dynamics. Section 5.3 further analyzes the sources of the model's quantitative performance.

\subsection{Cohort effects and asset returns}

According to the model, an individual agent's log consumption can be decomposed into cohort effects $\left(a_{s}\right)$, time effects $\left(b_{t}\right)$, and individual-specific effects $\left(\varepsilon_{t}^{i}, i \in\right.$ $\{e, w\})$ :

$\log c_{t, s}^{i}=a_{s}+b_{t}+\varepsilon_{t}^{i}$,

where, according to (22),

$a_{s}=\sum_{j \in\{e, w\}} \phi^{j} \log c_{s, s}^{j}+\frac{1}{\gamma} \log \left(C_{s}^{(1-\psi)(1-\gamma)} \beta^{-s} \xi_{s}\right)$,

$b_{t}=-\frac{1}{\gamma} \log \left(\xi_{t} \beta^{-t} C_{t}^{(1-\psi)(1-\gamma)}\right)$,

$\varepsilon_{s}^{i}=\log c_{s, s}^{i}-\sum_{j \in\{e, w\}} \phi^{j} \log c_{s, s}^{j}$.

The next lemma describes the evolution of the cohort effects according to the model.

Lemma 3. For any $T \geq 1$, the cohort effect in individual consumption satisfies

$a_{s+T}-a_{s}=-\sum_{i=1}^{T} \log \left(\frac{v\left(u_{s+i}\right)}{1-\lambda}\right)+z_{s+T}-z_{s}$,

where $z_{s}$ is a series of i.i.d. random variables defined by

$z_{s}=(1-\phi) \log \left(\frac{c_{s, s}^{w}}{Y_{s}}\right)+\phi \log \left\{\frac{c_{s, s}^{e}}{Y_{s}}\right\}$

Eq. (40) shows why cohort analysis is useful for our purposes. First, it allows us to test for the presence of perfect intergenerational risk sharing. Under perfect risk sharing across generations, all cohort effects are zero. The discussion at the end of Section 3.2 implies that, under perfect intergenerational risk sharing, individual consumption equals aggregate consumption per capita irrespective of cohort. Accordingly, individual consumption should exhibit time effects, but not cohort effects. In contrast, cohort effects are nonzero in our model and, moreover, they are non-stationary, since the first term on the right-hand side of (40) is a random walk with drift. As we discuss at greater length in the extended appendix (Section 3), these are robust and broad implications of most overlapping-generations models, since they depend exclusively on two aspects of the model: the "Euler equation" Eq. (22) and the fact that arriving generations obtain a stationary fraction of aggregate consumption.

Second, under the same two basic assumptions, the permanent shocks to the consumption cohort effects capture a central notion for our purposes: they isolate permanent variations in the stochastic discount factor that are due to the lack of perfect intergenerational risk sharing, rather than to permanent movements in aggregate output that are equally shared across generations. In the context of our model, this notion is captured by the $\log$ displacement factor $\log \left(v\left(u_{s+i}\right) /(1-\lambda)\right)$. Hence, Eq. (40) implies that by using standard econometric techniques to isolate the variance of the permanent increments of consumption cohort effects, we can obtain a measurement of the variance of the displacement factor.

Third, cohort effects allow us to exploit the crosssectional dimension of the Consumer Expenditure Survey (CEX) data set, rather than rely on its short time 
dimension. By using the cross-sectional dimension of CEX data, we can estimate cohort effects for individuals that were born as early as the first decades of the last century. This allows us to obtain a long time path of cohort effects (about 80 years). In light of Eq. (40), this long path contains information about the behavior of the displacement factor over the same period.

We estimate cohort effects in CEX data by running a regression of household log consumption on time and cohort dummies. A detailed description of the data is provided in Appendix B. To make our results robust to the presence of age effects in the data (for instance, due to borrowing constraints early in life, or changes in consumption patterns due to the aging of children), we also allow for age effects, which we model by including either flexible parametric spline functions of age or simply age dummies. We also include a control for log household size. As a robustness check, we also adjust for family size by dividing by the average family-equivalence scales reported in FernandezVillaverde and Krueger (2007). The two approaches produce very similar results, since our estimate for the coefficient of log family size implies an adjusted household consumption that is very similar to the average family-equivalence scales reported in Fernandez-Villaverde and Krueger (2007).

It is well understood in the empirical literature that linear trends in age, cohort, and time effects cannot be identified separately if age effects are included in Eq. (36). Some of the literature addresses this problem by following Deaton and Paxson (1994) and making the normalizing assumption that the time effects add up to zero and are orthogonal to the time trend. In our model, the time effects $b_{t}$ follow a random walk and, hence, such an assumption is not appropriate. However, it is possible to uniquely identify differences-in-differences of cohort effects $\left(a_{s+1}-a_{s}-\left(a_{s}-a_{s-1}\right)\right)$ without any normalizing assumptions and even after including a full set of age dummies (see McKenzie (2006) for a proof). The easiest way to see why identification is possible is to allow for age effects in Eq. (36) and note that equation $\log c_{t, s}^{i}=a_{s}+b_{t}+$ $\gamma_{t-s}+\varepsilon^{i}$ implies

$$
\begin{aligned}
& \mathrm{E} \log c_{t+1, s+1}^{i}-\mathrm{E} \log c_{t+1, s}^{i}-\left(\mathrm{E} \log c_{t, s}^{i}-\mathrm{E} \log c_{t, s-1}^{i}\right) \\
& \quad=a_{s+1}-a_{s}-\left(a_{s}-a_{s-1}\right) .
\end{aligned}
$$

Replacing the expectations on the left-hand side of (42) with the respective cross-sectional averages allows us to obtain (exactly identified) estimates of the differences-in-differences of cohort effects, as captured by the right-hand side of (42).

Under the null hypothesis that all cohort effects are zero $\left(a_{s}=0\right)$, so should be their differences-in-differences $\left(a_{s+1}-2 a_{s}+a_{s-1}=0\right)$. Hence, the first hypothesis we test is that $a_{s+1}-2 a_{s}+a_{s-1}=0$ for all $s$. The three columns of Table 1 report the results of estimating Eq. (36) including (a) no age effects, (b) parametric age effects, and (c) a full set of age dummies. The model with parametric age effects is fitted by assuming that age effects are given by a cubic spline with knots at ages 33,45 , and 61 . The first row reports the results from a Wald test of $a_{s+1}-2 a_{s}+$ $a_{s-1}=0$ for all $s$. The second row reports the associated $p$ values. The Wald test rejects the hypothesis that cohort effects are identically zero.

\section{Table 1}

Results from regression of log consumption on time dummies (one dummy for each quarter), annual cohort dummies, and various specifications of age effects.

Cohort $s$ is defined as the set of individuals of age 20 in year $s$. In the first specification the regression does not contain age effects, while the second specification allows age effects parameterized via a cubic spline. The third specification allows for a full set of age dummies. The Wald test refers to the test that $a_{s+1}-2 a_{s}+a_{s-1}=0$ for all $s$. Standard errors are computed using a robust covariance matrix clustered by cohort and

\begin{tabular}{|c|c|c|c|}
\hline & $\begin{array}{l}\text { No age } \\
\text { effects }\end{array}$ & $\begin{array}{c}\text { Parametric age } \\
\text { effects }\end{array}$ & $\begin{array}{c}\text { Age } \\
\text { dummies }\end{array}$ \\
\hline Wald test & 31.3 & 4.21 & 4.25 \\
\hline$\Delta a_{s+1}-\Delta a_{s}=0$ & & & \\
\hline$p$-Value & 0.000 & 0.000 & 0.000 \\
\hline Observations & 52245 & 52245 & 52245 \\
\hline$R$-squared & 0.373 & 0.382 & 0.384 \\
\hline
\end{tabular}
quarter.

We show the magnitude of the variation of the cohort effects in the first four rows of Table 2. The first row contains estimates of the standard deviation ${ }^{7}$ of the first differences in cohort effects, i.e., $\Delta a_{s+1} \equiv a_{s+1}-a_{s}$. Since $\Delta a_{s+1}$ is identified up to an additive constant, its standard deviation is identified. As we discussed above, permanent shocks to consumption cohort effects are equal to the log displacement factor in our model. The second row of the table reports estimates of the standard deviation of permanent shocks to consumption cohort effects, obtained using the methods of Beveridge and Nelson (1981) after fitting an ARIMA $(1,1,1)$ model to the estimated cohort effects. We report two additional estimates of the standard deviation of permanent shocks in the next two rows. The third row contains Newey-West estimates of the long-run variance of $\Delta a_{s}$ using ten lags. In the fourth row, we report the standard deviation of rolling ten-year averages of $\Delta a_{s}$, normalized by $\sqrt{10}$. The three estimates of the volatility of the permanent component of the cohort effects are similar to each other. These estimates form target moments for the calibration exercise of the next subsection.

The fifth and seventh rows in Table 2 relate increments in consumption cohort effects to cross-sectional differences in stock returns. According to our model, increments of the permanent component (the random-walk component) of cohort effects should co-vary positively with the growth-value return differential. We compute this growth-value return differential by taking the log-gross

\footnotetext{
${ }^{7}$ We use only cohorts from 1927-1995 for the calculations in Table 2, because cohorts prior to 1927 and after 1995 are not sufficiently populated. With this choice of sample, the minimal cohort has 199 observations, the first quartile of cohorts has 521 observations and the median cohort has 657 observations. Accordingly, cohorts are sufficiently well populated so that our variance estimate of the first differences of cohorts is not materially affected by sampling error. We would also like to point out that our estimates of the variance of permanent components of cohort effects are less affected by (i.i.d.) measurement error than the variance of first differences, because heteroskedasticity- and autocovariance-consistent variance estimators control for the moving-average error structure introduced by the noisy measurement of first differences.
} 
Table 2

Various moments of the permanent components of the estimated consumption cohort-effects.

Cohort effects are estimated allowing for both time and age dummies. The "growth-value" return differential refers to the log-gross return differential between the low and high book-to-market portfolio used by Fama and French (1993) in their construction of the "HML" factor. The " $p$-value" reported in the sixth and eighth row refers to the (one-sided) $p$-values for the quantities in rows five and seven (respectively) under the null hypothesis that the growth-value return differential is independent of the cohort differences. These $p$-values are computed using a block-bootstrap procedure. Specifically, we simulate 50,000 artificial paths of growth-value return differentials by drawing blocks (average block size: 5 years) from their empirical cumulative distribution function, as described in Politis and Romano (1994). Then we compute the analog of the expressions in rows five and seven (respectively) for each bootstrap repetition and use them to compute $p$-values.

\begin{tabular}{lc}
\hline Std. dev. (Cohort-Lagged Cohort) & 0.030 \\
Std. dev. (Perm. Component (Beveridge Nelson)) & 0.023 \\
Std. dev. (Perm. Component (Newey West)) & 0.020 \\
Std. dev. (Perm. Component $\sqrt{10}(10$-year Aveg)) & 0.018 \\
$\frac{\text { Cov(coh.diffs; growth-value) (Newey West) }}{\text { Var(coh.diffs) }}$ & 3.92 \\
$p$-Value & 0.026 \\
Cov(10-year coh.diffs; 10-year growth-value) & 3.43 \\
p-Value Var(10-year coh.diffs) & 0.048 \\
Observations & 68
\end{tabular}

return differential between the low and high book-tomarket portfolios used by Fama and French (1993) in their construction of the "high-minus-low" (HML) factor. In the fifth row of Table 2 we use the Newey-West variancecovariance matrix to estimate the covariance between the permanent component of cohort effects and the growthvalue return differential, normalized by the long-run variance of the consumption cohort effects as obtained in the third row of the table. As a robustness check, we also report in the seventh row of the table the results from computing the covariance of ten-year consumption cohort differences and ten-year cumulative returns on the growth-value returns, normalized by the variance of tenyear consumption-cohort differences. We test the null hypothesis that growth-value returns are independent from cohort differences. The sixth and eighth rows report the $p$-values for the statistics in rows five and seven, respectively, using the block-bootstrap procedure of Politis and Romano (1994). We have implemented their procedure for average blocks of observations ranging between one and ten years, and in all cases the resulting $p$-values are below five percent. Besides providing statistical evidence in favor of the model, the quantities in the fifth and seventh rows form targets for the calibration exercise in the next section.

Fig. 2 illustrates the results of Table 2. The figure depicts the estimated cohort effects against the cumulative sum of the growth-value return differential. We report the cohort effects from 1927 onward, because data on the Fama-French growth-value return differential are available from 1927 onwards. We report results up to 1995 because of the sparsity of data on cohorts post- 1995 . Since cohort effects are only identified up to a linear trend, we remove a deterministic trend from both series as a normalization. According to Eq. (40), the permanent component of the cohort effects is identical to the (negative of) cumulative sum of the log displacement factor, which in turn should be correlated with the cumulative sum of the growth-value logarithmic return differential. The left panel of the figure suggests such covariation. The right panel of Fig. 2 is identical to the left panel, except that we split the sample into pre-1945 and post-1945 subsamples and remove two separate deterministic trends in the two subsamples.

Table 3 reports further results on the relationship between consumption cohort effects, innovation activity, and stock returns. Specifically, the first row in Table 3 reports the average difference between the log-gross return on the first nine book-to-market decile portfolios and the respective return on the 10th-decile portfolio. The second row of Table 3 reports the estimates of the betas of these return differences with respect to the increments of the permanent component of log consumption cohort effects. Stocks in low book-to-market deciles (growth stocks) have lower average returns than stocks in high book-to-market deciles (value stocks), which is the wellknown value premium. The second row of the table shows that displacement-risk exposure decreases across the book-to-market deciles, and, therefore, growth stocks offer a hedge against the displacement risk. The third row explores an additional implication of the model, namely that the return differential between value and growth stocks is related to innovation activity. Using increases in the aggregate stock of trademarks as a proxy for innovation activity, we report the betas of portfolio differentials on the (percentage) increments in trademarks. ${ }^{8}$ The declining pattern of these betas is consistent with the model. These betas remain practically unchanged when we include aggregate consumption growth as an additional regressor and compute "multifactor betas."

The extended appendix (Section 9) explores in yet another way the plausibility of the link between the value-growth differential and technological innovation. According to our theory, epochs of large technological innovation should be associated with a low value-growth return differential. Accepting the popular notion that the late 1980 s and the 1990s were times of accelerated technological innovation due to the IT revolution, we argue that this differential declined substantially during that period. Moreover, we find that this decline was not just an aberration of the US data, but is also present in international data. This internationally correlated decline in the relative performance of value and growth stocks is consistent with the notion of accelerated displacement due to the worldwide spread of IT.

Since the displacement risk in the model is generated partly by shocks to agents' human capital, as an additional test of the model's mechanism we estimated cohort effects in individual earned income. According to Eqs. (10) and (11), the cohort effects in income data should be

\footnotetext{
${ }^{8}$ We are grateful to Frederico Belo for providing us the data on trademarks and suggesting this additional test of the model's mechanism.
} 

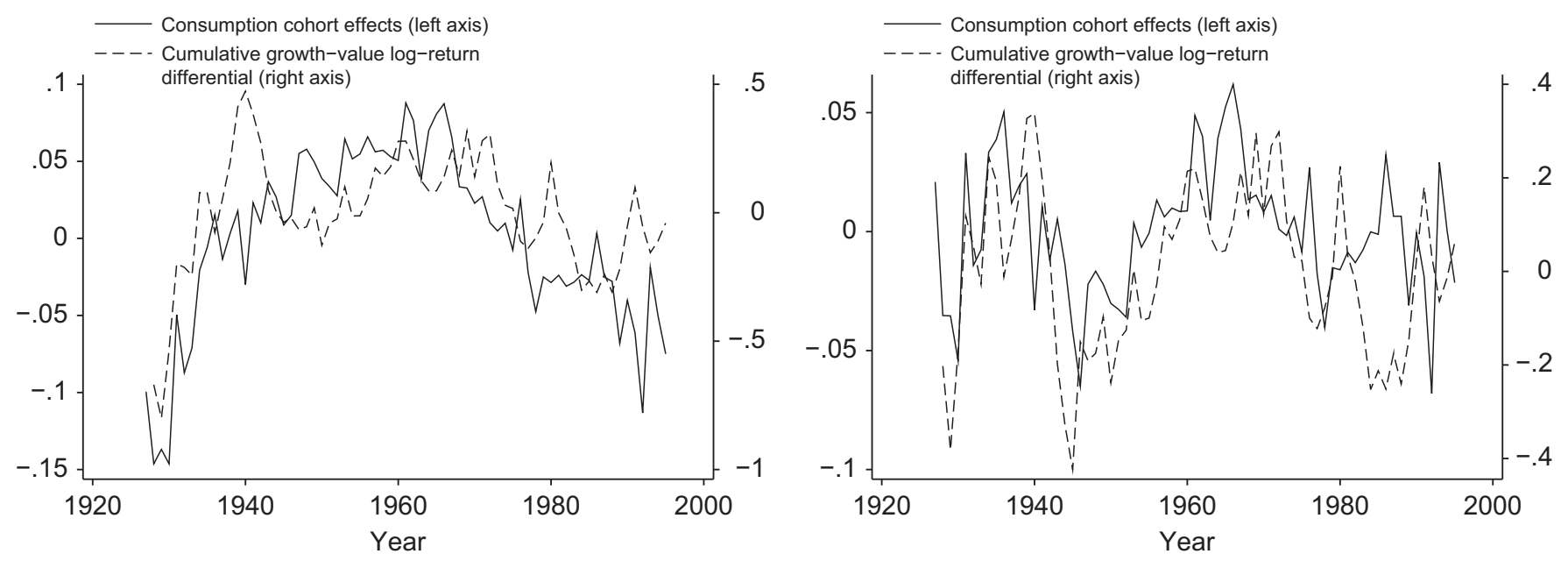

Fig. 2. Left panel: consumption cohort effects and cumulative log-returns on a growth-value portfolio after removing constant time trends from both series. Right panel: same as left panel, except that we split the sample into pre-1945 and post-1945 subsamples and remove two separate deterministic trends in the two subsamples. A full set of time and age dummies was used in estimating the consumption cohort effects.

Table 3

Average of returns on long-short book-to-market decile portfolios and their betas with respect to the permanent component of consumption-cohort innovations $\left(\beta_{1}\right)$ and percentage increases in trademarks $\left(\beta_{2}\right)$.

The first row reports average annual returns. The label $n-10$ denotes the average log return on a portfolio long the stocks in the $n$th decile and short those in the 10 th decile. The second row $\left(\beta_{1}\right)$ reports the covariances between these returns and innovations in the permanent component of log consumption cohort effects, normalized by the long-run variance of the latter. To isolate permanent components, covariances and variances are computed using the Newey-West approach with 10 lags. The third row $\left(\beta_{2}\right)$ reports coefficients from regressing the respective portfolio differentials on the percentage increase in trademarks. The data on returns are from K. French's website (Annual 1927-2010). The data on consumption cohorts are from the Consumption Expenditure Survey. The compilation of trademark data follows Greenwood and Uysal (2005) and covers the time-frame 1930-2000.

\begin{tabular}{lccccccccc}
\hline Portfolio & $1-10$ & $2-10$ & $3-10$ & $4-10$ & $5-10$ & $6-10$ & $7-10$ & $8-10$ & -10 \\
\hline Mean log return & -0.034 & -0.020 & -0.021 & -0.026 & -0.014 & -0.014 & -0.016 & 0.001 \\
$\beta_{1}$ & 6.293 & 7.162 & 5.609 & 4.995 & 5.125 & 4.184 & 3.090 \\
$\beta_{2}$ & 1.744 & 1.822 & 1.980 & 1.258 & 1.163 & 1.379 & 1.138 & 0.153 & -0.129 \\
\hline
\end{tabular}

correlated with the cumulative return of a growth-minusvalue portfolio.

We define earned income empirically as disposable income net of capital gains, dividends, taxes, and transfers. We relate earned income to stock market returns in the same manner as we did with consumption cohort effects. Consistent with the model, the results using earned-income cohort effects are very similar to the results using consumption cohort effects and we omit them to save space.

Before proceeding with a calibration of the model, we make two final remarks on the robustness of identifying displacement risk through the permanent component of consumption cohort effects.

First, by using cohort analysis, we can overcome the small number of observations per household in the CEX. Specifically, the CEX is not a true panel of consumption growth. Instead, it is a repeated cross-section, and it provides information for the consumption of the same household for at most a year. Existing literature (e.g., Cogley, 2002) has used the three quarterly observations of consumption growth available per household in the CEX to form a measure of the average quarterly consumption growth of existing agents. As we show in the extended appendix (Section 5), this quarterly measure of “existing” agents' consumption growth is likely to lead to non-robust asset-pricing inferences if some agents are sluggish in adjusting their consumption. In the extended appendix, we illustrate our results for the special case where sluggishness is due to inattention, but similar arguments would apply for other short-run frictions. We also show that our methodology, which bases inferences on the permanent component of cohort effects, is robust to such short-run frictions.

Second, our focus on the permanent component of cohort effects makes our model robust to certain stylized assumptions of the model. To give an example, the model assumes that the benefits of innovation accrue to the incoming generation. In reality, it is likely that not only the current incoming generation profits from innovation, but also generations "close" to the incoming one. The extended appendix (Section 4) considers such an extension, whereby innovation acts as a positive endowment shock not just for the incoming generation but also for some existing agents. Similar to the incoming generations' inability to trade in markets before it is born, existing agents are prevented from fully trading the innovationrelated risks because of borrowing constraints early in life. We find that extending the model in such a direction alters the short-run dynamics of cohort effects and changes the short-run dynamics of the stochastic discount factor. However, the permanent component of cohort 
Table 4

Baseline parameters used in the calibration.

We discuss the choice of the parameter values in Section 5.2.

\begin{tabular}{cccc}
\hline$\beta$ & 0.999 & $k$ & 0.25 \\
$\psi$ & 0.5 & $v$ & 0.05 \\
$\mu$ & 0.015 & $\rho$ & 0.9 \\
$\sigma$ & 0.032 & $\kappa$ & 0.9 \\
$\alpha$ & 0.8 & $\chi$ & 4 \\
$\lambda$ & 0.018 & $\varpi$ & 0.87 \\
$\delta$ & 0.012 & $\eta$ & 0.9 \\
\hline
\end{tabular}

effects still reflects the permanent variations in the stochastic discount factor due to imperfect intergenerational risk sharing. Indeed, this link between the permanent component of cohort effects and the stochastic discount factor continues to hold in models featuring age-dependent, transient frictions that introduce imperfect correlation between the consumption growth rates of existing cohorts. Since the permanent component of the stochastic discount factor governs the behavior of longrun returns (Hansen, Heaton, and Li, 2008), our quantitative results are likely to be robust to such realistic extensions, especially for returns over longer holding periods.

\subsection{Calibration}

Our empirical results suggest that the key predictions of the model are qualitatively consistent with the data. In this section we assess whether the model can account quantitatively for the empirical relationships between asset returns, aggregate consumption growth, and consumption cohort effects.

Our parameter choices are summarized in Table 4 . The values of $\mu$ and $\sigma$ are chosen to approximately match the moments of aggregate consumption growth. The parameter $\alpha$ controls the share of profits in aggregate income in the model, according to Eq. (45). We set $\alpha=0.8$, which implies a profit share of $16 \%$. In yearly NIPA data for the U.S. since 1929, the average share of (after-depreciation) profits and interest payments is about $15 \%$ of national income, or $18 \%$ if one imputes that one-third of proprietor's income is due to profits. ${ }^{9}$ The parameter $\lambda$ is chosen to capture the arrival of new agents. In post-war data, the average birth rate is about 0.016 . Immigration rates are estimated to be between $0.002-0.004$, which implies an overall arrival rate of new agents between 0.018 and 0.02 . We take the time-discount factor to be close to one, since in an overlapping-generations model the presence of

${ }^{9}$ Since in our model there is no financial leverage, it seems appropriate to combine dividend and interest payments. Moreover, it also seems appropriate to deduct depreciation from profits, because otherwise the relative wealth of agents $e$ and $w$ would be unduly affected by a quantity that should not be counted as income of either. We note here that our choice of a profit share of $16 \%$ is consistent with the real business cycle literature, which assumes a capital share (i.e., profits prior to depreciation) of one-third and deducts investment from gross profits to obtain dividends. Since, in stochastic steady state, investment and depreciation are typically close to each other, the share of net output that accrues to firm owners is approximately equal to the number we assume here. death makes the "effective" discount factor of agents equal to $\beta(1-\lambda)$. Given a choice of $\lambda=0.02$, the effective discount rate is 0.98 , which is a standard choice in the literature. The constant $\psi$ influences the growth rate of agents' marginal utilities, and hence is important for the determination of interest rates. We choose $\psi=0.5$ in order to approximately match observed interest rates. On behavioral grounds, this assumption implies that an individual places equal weights on his own consumption and on his consumption relative to the aggregate. In the online extended appendix (Section 10), we investigate the model's performance when agents have standard CRRA preferences. With the exception of the interest rate, which becomes $5.7 \%$, the model's performance is slightly improved along all dimensions.

In the real world, income is hump-shaped as a function of age, whereas in the model, age effects are assumed to follow a geometric trend. Since an agent's initial consumption-and hence the stochastic discount factor-is affected by the present value of earnings over the life cycle, we calibrate $\delta$ so that, inside the model, the present value of income computed using the empirical age-earnings profile coincides with the one computed using a simple geometric trend with parameter $\delta$. Specifically, we use the estimated age-log earnings profiles of Hubbard, Skinner, and Zeldes (1994) and determine $\delta$ so that

$$
\begin{gathered}
\mathrm{E}_{s} \sum_{t=s}^{\infty}(1-\lambda)^{t-s}\left(\frac{\xi_{t}}{\xi_{s}}\right)\left(\frac{w_{t}}{w_{s}}\right)(1+\delta)^{t-s}\left(\frac{A_{t}}{A_{s}}\right)^{-\rho} \\
=\mathrm{E}_{s} \sum_{t=s}^{\infty} \Lambda_{t-s} G_{t-s}\left(\frac{\xi_{t}}{\xi_{s}}\right)\left(\frac{w_{t}}{w_{s}}\right)\left(\frac{A_{t}}{A_{s}}\right)^{-\rho},
\end{gathered}
$$

where $\Lambda_{t-s}$ is an agents' survival probability at age $t-s+20$ (conditional on surviving until age 20) obtained from the National Center for Health Statistics and $G_{t-s}$ is the age-earnings profile, as estimated by Hubbard, Skinner, and Zeldes (1994).

The innovation shocks $u_{t}$ are drawn from a Gamma distribution with parameters $k$ and $v$. Parameters $\rho$ and $\chi$ control the exposures of labor and dividend income to the shock $u_{t}$. We choose $k, v, \rho$, and $\chi$ jointly to approximately match (a) the volatility of the permanent component of consumption cohort effects as reported in Table 2, (b) the volatility of the permanent component of income cohort effects, (c) the volatility of dividend growth of the market portfolio, and (d) the correlation between dividend growth of the market portfolio and aggregate consumption. We obtain the permanent component of income cohort effects by using earned log income on the left-hand side of Eq. (36), estimating the resulting cohort effects, and isolating their permanent component, as we did for consumption.

The parameter $\kappa$ controls the proportion of growth opportunities owned by existing firms, which are therefore tradeable, while $\varpi$ controls the decay of existing firms' growth opportunities (low $\varpi$ means that growth opportunities are front-loaded). As a consequence, these two parameters jointly determine the aggregate price-to-earnings ratio, as well as the return properties of growth firms. We therefore calibrate them to the 
aggregate price-to-earnings ratio and the covariance between the growth-value return differential and the log displacement factor, as estimated in the previous subsection. We chose this covariance as a target in calibration because it is directly linked (through the consumer's Euler equation) to the average value premium. The online extended appendix (Section 10) shows that our results are robust to alternative parameter choices, e.g., lower values of $\kappa$.

The parameter $\eta$ affects only the relative weight of assets in place and growth opportunities in firms' values, but it does not affect any aggregate quantity. Therefore, we use it to calibrate the cross-sectional spread in priceto-earnings ratios between the top and the bottom priceto-earnings deciles of firms.

We treat the risk-aversion coefficient $\gamma$ as a free parameter and examine the model's ability to match a number of moments of asset returns and fundamentals for a range of values of $\gamma$. As can be seen in Table 5 , with $\gamma=10$ the model can match the value premium well, and it can also match about two-thirds of the equity premium. In interpreting these results, it should be noted that the model has no financial leverage. As Barro (2006) argues, in the absence of financial leverage, the model-implied equity premium should be about two-thirds of the equity premium observed in the data (since, in reality, equity is levered). Moreover, in the model there is no time variation in interest rates, stock return volatility, and the conditional equity premium. Therefore, it is not surprising that the model needs relatively high levels of risk aversion to match the data. However, even in the absence of time-varying conditional moments of returns, levels of risk aversion around ten explain a substantial fraction of return moments. Therefore, the evidence in Table 5 suggests that the model's mechanisms are quantitatively powerful enough to match the salient moments of asset returns and macroeconomic fundamentals.

\subsection{Inspecting the mechanism}

Compared to standard, infinitely-lived-agent models of asset pricing, our model produces larger equity and value premiums. The main reason for this outcome is that current firms' dividends are much more volatile than aggregate consumption, and exhibit a high exposure to displacement risk-a risk that is priced.

A simple back-of-the-envelope calculation helps illustrate this statement. Taking logarithms of the pricing kernel in Eq. (25), using (4), (20), and the definition of $v\left(u_{t+1}\right)$ in Eq. (26) leads to

$$
\begin{gathered}
\Delta \log \xi_{t+1}+\text { const }=\underbrace{(\psi(1-\gamma)-1) \varepsilon_{t+1}}_{\text {std. dev.: } 0.18} \\
+\underbrace{(\psi(1-\gamma)-1)(1-\alpha) u_{t+1}-\gamma \log \left(v\left(u_{t+1}\right)\right)}_{\text {std. dev.: } 0.24} .
\end{gathered}
$$

The numbers under the two components in Eq. (43) are the annual standard deviation of each term. The stochastic component of returns on the aggregate stock-market portfolio equals $\varepsilon_{t+1}+f\left(u_{t+1}\right)$, where $f\left(u_{t+1}\right)$ is an appropriate function of the displacement shock. The volatility of $\varepsilon_{t}$ is 0.032 and the volatility of $f\left(u_{t+1}\right)$ is approximately 0.095 .

In our model, the volatility of stock-market returns owes entirely to dividend-growth volatility, which is equal to $\sqrt{0.032^{2}+0.095^{2}}=0.1$. The model generates higher volatility of stock-market returns than that of aggregate consumption growth because future dividends of existing firms are not cointegrated with future aggregate consumption, or even with existing agents' consumption. This lack of cointegration allows dividend growth to be much more volatile than aggregate consumption growth, with both driven by permanent shocks.

Table 5

Annual data and model moments for different values of risk aversion $\gamma$.

Data on consumption, the riskless rate, the equity premium, and dividends per share are from Campbell and Cochrane (1999). Data on the aggregate $E / P$ ratio are from the long sample (1871-2005) on R. Shiller's website. The $E / P$ for value and growth firms are the respective $E / P$ ratios of firms in the bottom and top book-to-market deciles from Fama and French (1992). The value premium is computed as the difference in value weighted returns of stocks in the top and bottom book-to-market deciles, available from the website of Kenneth French (1927-2010). "Growth-value" refers to the differential log returns between growth and value stocks, as described in Table 2 . We perform an analogous computation inside the model. Std ( $\Delta a_{s}^{\text {perm }}$ ) denotes the standard deviation of the permanent component of consumption cohort effects as estimated in Table 2 . Std ( $\Delta w_{s}^{\text {perm }}$ ) refers to the cohort

\begin{tabular}{|c|c|c|c|c|}
\hline & Data & $\gamma=10$ & $\gamma=12$ & $\gamma=15$ \\
\hline Aggregate log consumption growth rate & 0.017 & 0.017 & 0.017 & 0.017 \\
\hline Aggregate log consumption volatility & 0.033 & 0.032 & 0.032 & 0.032 \\
\hline Riskless rate & 0.010 & 0.022 & 0.015 & 0.014 \\
\hline Equity premium & 0.061 & 0.040 & 0.051 & 0.067 \\
\hline Aggregate earnings/price & 0.075 & 0.103 & 0.108 & 0.125 \\
\hline Dividend volatility & 0.112 & 0.108 & 0.108 & 0.108 \\
\hline Correl. (divid. growth, cons.growth) & 0.2 & 0.145 & 0.145 & 0.145 \\
\hline $\operatorname{Std}\left(\Delta a_{s}^{\text {perm }}\right)$ & 0.023 & 0.027 & 0.026 & 0.024 \\
\hline $\operatorname{cov}\left(\Delta a_{s}^{\text {perm }}\right.$, growth-value $)$ & 3.92 & 4.24 & 4.39 & 4.72 \\
\hline \multicolumn{5}{|l|}{$\overline{\operatorname{var}\left(\Delta a_{s}^{\mathrm{perm}}\right)}$} \\
\hline $\operatorname{Std}\left(\Delta w_{s}^{\text {perm }}\right)$ & 0.022 & 0.021 & 0.021 & 0.021 \\
\hline Earnings/price 90th perc. & 0.120 & 0.111 & 0.118 & 0.139 \\
\hline Earnings/price 10 th perc. & 0.04 & 0.041 & 0.039 & 0.042 \\
\hline Average value premium & 0.065 & 0.064 & 0.081 & 0.105 \\
\hline Std. dev. of growth-value & 0.127 & 0.110 & 0.110 & 0.110 \\
\hline
\end{tabular}
effects of earned income. $\mathrm{E}\left(R^{a}-R^{o}\right)$ is the expected return difference between assets in place and growth opportunities. Model-implied moments are computed by estimating expectations via numerical integration whenever possible, otherwise by using simulation ( 10,000 years). 
Such long-run dynamics of dividends and aggregate consumption are mutually consistent. Dividends of existing firms become a negligible fraction of aggregate consumption over time, while the aggregate dividends paid by all firms at any point in time are a constant fraction of aggregate consumption.

Given the above volatilities of the components of aggregate market returns and the stochastic discount factor, if all these components were jointly normally distributed, then the equity premium would equal approximately $0.18 \times 0.032+0.24 \times 0.095=0.029$. The difference between this number and the equity premium of 0.04 in our base-case calibration owes to the fact that the shock $u_{t+1}$, and the terms dependent on $u_{t+1}$, are not Gaussian, making the consumption growth of existing agents and the stock-market returns co-skewed.

Finally, we would like to note that, while displacement shocks also affect equilibrium pricing of risk by making existing agents' consumption growth more volatile than the aggregate consumption growth, this effect is relatively weak. We calibrate our model to reproduce the empirical volatility of permanent cohort effects in consumption, thus identifying the additional consumption volatility introduced by displacement shocks. The resulting volatility of existing agents' consumption growth is only slightly higher than the volatility of aggregate consumption (0.039 versus 0.032 ). Thus, displacement shocks generate a high equity premium by making dividends of existing firms and their returns strongly exposed to displacement risk, not by making the consumption of existing agents substantially more volatile than aggregate consumption. It is also noteworthy that the volatilities of both aggregate consumption and existing agents' consumption can be reduced further-without substantively affecting our results-by reducing the volatility of the total-factor-productivity shock $\varepsilon_{t}$. Quantitatively, the shock $\varepsilon_{t}$ plays only a minor role in our calibration.

The above observations help us relate the optimal financial portfolio holdings of agents in the model to the composition of their total wealth, in particular, to the ratio of their financial capital to their total wealth. We provide a brief intuitive argument below and present the mathematical details in the extended appendix (Section 7).

As we discuss above, the dividends of existing firms are more exposed to displacement risk than the consumption of existing agents. Given that all valuation ratios and the consumption-to-wealth ratios for all the agents in our model are constant in equilibrium, it follows that the aggregate financial capital is more exposed to displacement risk than the total aggregate wealth. Because the total aggregate wealth consists of the aggregate financial and human capital, we conclude that the aggregate financial capital is more exposed to displacement risk that the aggregate human capital. Consequently, agents with high levels of financial wealth relative to their total wealth exhibit a higher demand for insurance against displacement risk than agents whose financial wealth is a relatively low proportion of their total wealth. An intuitive implementation of insurance against displacement shocks is through a growth tilt in the agents' stock portfolios, with the insurance premium given by the equilibrium value premium. In summary, we find that in our model agents with relatively high shares of financial capital in their total wealth composition implement a growth tilt in their stock portfolios, while the agents with relatively high shares of human capital implement a value tilt.

\section{Conclusion}

Innovation activity raises productivity and aggregate output. The benefits of innovative activity, however, are unequally shared. In an overlapping-generations model where the young benefit more from innovative activity than the old, and existing agents cannot trade with unborn generations, we show that the process of innovation can give rise to a new risk factor, the displacement risk factor. At a qualitative level, this factor can help raise the equity premium in aggregate time-series data and explain the return differential between value and growth stocks in cross-sectional data.

Cross-sectional consumption data allow us to test quantitatively for the presence, and measure the magnitude, of the displacement risk factor. Our empirical results suggest that displacement risk is nontrivial and is related to the return differential between the growth and value portfolios used by Fama and French (1993) in their construction of the "HML" factor. Our calibration exercises suggest that this new source of risk is quantitatively important enough to explain significant fractions of the equity and the value premiums.

Our model abstracts from many elements of asset-price behavior, intergenerational transfers, life-cycle effects, crosssectional characteristics of firms, etc., to highlight the economic intuition behind the displacement risk factor. Our framework can be enriched to incorporate some of these elements as well as extended in a number of other directions. We leave such extensions for future work.

\section{Appendix A. Auxiliary results and proofs}

Proof of Proposition 1. Consider the intermediate-good markets. We first derive the demand curve of the finalgood firm for the intermediate input $j$ at time $t$. Maximizing (6) with respect to $x_{j, t}$, we obtain

$x_{j, t}=L_{t}^{F}\left[\frac{p_{j, t}}{\omega_{j, t} Z_{t} \alpha}\right]^{1 /(\alpha-1)}$.

Substituting this expression into (8) and maximizing over $p_{j, t}$ leads to

$p_{j, t}=\frac{w_{t}}{\alpha}$,

while combining (44) and (45) yields

$x_{j, t}=L_{t}^{F}\left[\frac{w_{t}}{\omega_{j, t} Z_{t} \alpha^{2}}\right]^{1 /(\alpha-1)}$.

Next, consider the labor markets. Maximizing (6) with respect to $L_{t}^{F}$ gives the first-order condition

$w_{t} L_{t}^{F}=(1-\alpha) Y_{t}$. 
Substituting (46) into (3) and then into (47) and simplifying yields

$w_{t}=\left(\alpha^{2}\right)^{\alpha}\left(\frac{1-\alpha}{1+\chi}\right)^{1-\alpha} Z_{t} A_{t}^{1-\alpha}$.

We substitute Eq. (48) into (46) and then into (18) to obtain

$x_{j, t}=\frac{1+\chi}{A_{t}}\left(\frac{j}{A_{t}}\right)^{\chi} \frac{(1-\phi) \alpha^{2}}{\alpha^{2}+1-\alpha}$,

$L_{t}^{F}=\frac{1-\alpha}{\alpha^{2}+1-\alpha}(1-\phi)$.

Aggregate output is given by (20), which we derive by combining (49) and (50) inside (3). The fact that $\pi_{t}^{F}=0$ is an immediate implication of constant returns to scale in the production of final goods. Eq. (21) is obtained by combining (49) and (45) with (8) and (48). Total wages $w_{t}(1-\phi)$ equal $\left(\alpha^{2}+1-\alpha\right) Y_{t}$, which follows from (48) and (20). Finally, integrating (21) to obtain $\int_{0}^{A_{t}} \pi_{j, t}^{I} d j$ implies that aggregate profits equal $\alpha(1-\alpha) Y_{t}$.

Proposition 2. Let $\zeta$ be defined as

$\zeta \equiv \beta(1-\lambda)^{\gamma} e^{\mu \psi(1-\gamma)+\left(\sigma^{2} / 2\right) \psi^{2}(1-\gamma)^{2}}$

and consider the solution to the following system of three equations in three unknowns $\theta^{e}, \theta^{w}$, and $\theta^{g}$ :

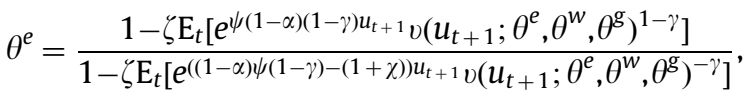

$\theta^{w}=\frac{1-\zeta \mathrm{E}_{t}\left[e^{\left.\psi(1-\alpha)(1-\gamma) u_{t+1} v\left(u_{t+1} ; \theta^{e}, \theta^{w}, \theta^{g}\right)^{1-\gamma}\right]}\right.}{1-\zeta(1-\lambda)(1+\delta) \mathrm{E}_{t}\left[e^{\left.((1-\alpha) \psi(1-\gamma)-\rho) u_{t+1} v\left(u_{t+1} ; \theta^{e}, \theta^{w}, \theta^{g}\right)^{-\gamma}\right]},\right.}$,

$\theta^{g}=\frac{\zeta \mathrm{E}_{t}\left[e^{(1-\alpha) \psi(1-\gamma) u_{t+1}} v\left(u_{t+1} ; \theta^{e}, \theta^{w}, \theta^{g}\right)^{-\gamma}\left(1-e^{-(1+\chi) u_{t+1}}\right)(1-\kappa)\right]}{1-\varpi \zeta \mathrm{E}_{s}\left[e^{(1-\alpha) \psi(1-\gamma) u_{t+1}} v\left(u_{t+1} ; \theta^{e}, \theta^{w}, \theta^{g}\right)^{-\gamma}\right]}$.

Here,

$v\left(x ; \theta^{e}, \theta^{w}, \theta^{g}\right) \equiv 1-\theta^{e} \alpha(1-\alpha)\left(\kappa\left(1-e^{-(1+\chi) x}\right)+(1-\varpi) \theta^{g}\right)$

$$
-\theta^{w}\left(\alpha^{2}+1-\alpha\right)\left(1-(1-\lambda)(1+\delta) e^{-\rho x}\right) .
$$

Assuming positivity of the numerators and denominators in (51) and (52) and positivity of the denominator in (53), there exists an equilibrium with stochastic discount factor

$\frac{\xi_{t+1}}{\xi_{t}}=\beta\left(\frac{Y_{t+1}}{Y_{t}}\right)^{-1+\psi(1-\gamma)}\left[\frac{1}{1-\lambda} v\left(u_{t+1} ; \theta^{e}, \theta^{w}, \theta^{g}\right)\right]^{-\gamma}$.

Proof of Proposition 2. To prove Proposition 2 we conjecture that the expression $c_{t+1, t+1}^{i} / Y_{t+1}$ is exclusively a function of $u_{t+1}$, and then confirm our conjecture based on the resulting expression for $\xi_{t+1} / \xi_{t}$. To start, we note that if $c_{t+1, t+1}^{i} / Y_{t+1}$ is exclusively a function of $u_{t+1}$, then an appropriate function $f\left(u_{t+1}\right)$ exists such that the stochastic discount factor is given by $\xi_{t+1} / \xi_{t}=\beta$ $\left(Y_{t+1} / Y_{t}\right)^{-1+\psi(1-\gamma)} \times f\left(u_{t+1}\right)$.

To determine $c_{t+1, t+1}^{i}$ for a worker $(i=w)$ under this conjecture for $\xi_{t+1} / \xi_{t}$, we use (22), (10), and the fact that $h_{t, s}=\bar{h}(1+\delta)^{t-s} \quad$ inside the intertemporal budget constraint (14) to obtain

$c_{s, s}^{w}=\bar{h} q_{s, s} w_{s}\left[\frac{\mathrm{E}_{s} \sum_{t=s}^{\infty}(1-\lambda)^{t-s}\left(\frac{\xi_{t}}{\xi_{s}}\right)\left(\frac{w_{t}}{w_{s}}\right)(1+\delta)^{t-s}\left(\frac{A_{t}}{A_{s}}\right)^{-\rho}}{\mathrm{E}_{s} \sum_{t=s}^{\infty}(1-\lambda)^{t-s}\left(\frac{\xi_{t}}{\xi_{s}}\right)\left(\frac{Y_{t}^{(1-\psi)(1-\gamma)}}{Y_{s}^{(1-\psi)(1-\gamma)}} \beta^{-(t-s)} \frac{\xi_{t}}{\xi_{s}}\right)^{-1 / \gamma}}\right]$.

Under our conjecture, the expression $\xi_{t+1} / \xi_{t}$ is a deterministic function of $\varepsilon_{t+1}$ and $u_{t+1}$, and it follows that the distribution of $\xi_{t} / \xi_{s}$ for $t \geq s$ depends only on $t-s$. The same is true for $A_{t} / A_{s}$ and for $w_{t} / w_{s}$ (by Eq. (48)). Therefore, the expectations in both the numerator and the denominator inside the square brackets of Eq. (56) are time-invariant constants. Hence, using (10) we can express (56) as

$c_{s, s}^{w}=\bar{h}\left(1-(1-\lambda)(1+\delta) e^{-\rho u_{s}}\right) w_{s} \theta^{w}$,

where $\theta^{w}$ is defined as

$\theta^{w} \equiv \frac{\mathrm{E}_{s} \sum_{t=s}^{\infty}(1-\lambda)^{t-s}\left(\frac{\xi_{t}}{\xi_{s}}\right)\left(\frac{w_{t}}{w_{s}}\right)(1+\delta)^{t-s}\left(\frac{A_{t}}{A_{s}}\right)^{-\rho}}{\mathrm{E}_{s} \sum_{t=s}^{\infty}(1-\lambda)^{t-s}\left(\frac{\xi_{t}}{\xi_{s}}\right)\left(\frac{Y_{t}^{(1-\psi)(1-\gamma)}}{Y_{s}^{(1-\psi)(1-\gamma)}} \beta^{-(t-s)} \frac{\xi_{t}}{\xi_{s}}\right)^{-1 / \gamma}}$,

governing the ratio between the value of earned wages and consumption.

The initial consumption of new business owners born at time $s$ can be computed in a similar fashion. To start, we observe that

$\Pi_{j, s}^{I}=\pi_{j, s}^{I}\left[\mathrm{E}_{s} \sum_{t=s}^{\infty}\left(\frac{\xi_{t}}{\xi_{s}}\right)\left(\frac{\pi_{j, t}^{I}}{\pi_{j, s}^{I}}\right)\right]$.

Our conjecture on $\xi_{t+1} / \xi_{t}$ and (21) imply that the expression inside square brackets in (59) is a constant. Observing that $A_{s}-A_{s-1}=A_{s}\left(1-e^{-u_{s}}\right)$ (from (9)) and that $\int_{A_{s-1}}^{A_{s}} \pi_{j, s}^{I} d j=\left(1-e^{-(1+\chi) u_{s}}\right) \alpha(1-\alpha) Y_{s}$ (from (21)), and using (59) inside (17) gives

$$
\begin{aligned}
V_{s, s}= & \alpha(1-\alpha) Y_{s} \times\left\{\mathrm{E}_{s} \sum_{t=s}^{\infty}\left(\frac{\xi_{t}}{\xi_{s}}\right)\left(\frac{\pi_{t}^{I}}{\pi_{s}^{I}}\right)\right\} \\
& \times\left\{\kappa\left(1-e^{-(1+\chi) u_{s}}\right)+(1-\varpi) \mathrm{E}_{s} \sum_{t=s+1}^{\infty}\left(\frac{\xi_{t}}{\xi_{s}}\right)\right. \\
& \left.\times\left(\frac{Y_{t}}{Y_{s}}\right)(1-\kappa)\left(1-e^{-(1+\chi) u_{t}}\right) \varpi^{t-s-1}\right\} .
\end{aligned}
$$

It will be useful to define

$$
\theta^{e} \equiv \frac{\mathrm{E}_{s} \sum_{t=s}^{\infty}\left(\frac{\xi_{t}}{\xi_{s}}\right)\left(\frac{\pi_{t}^{I}}{\pi_{s}^{I}}\right)}{\mathrm{E}_{s} \sum_{t=s}^{\infty}(1-\lambda)^{t-s}\left(\frac{\xi_{t}}{\xi_{s}}\right)\left(\frac{Y_{t}^{(1-\psi)(1-\gamma)}}{Y_{s}^{(1-\psi)(1-\gamma)}} \beta^{-(t-s)} \frac{\xi_{t}}{\xi_{s}}\right)^{-1 / \gamma}},
$$

which, in analogy to $\theta^{w}$, governs the ratio between the values of future dividends (therefore, cashflows to an entrepreneur owning a value firm) and consumption, and

$\theta^{g} \equiv \mathrm{E}_{s} \sum_{t=s+1}^{\infty}\left(\frac{\xi_{t}}{\xi_{s}}\right)\left(\frac{Y_{t}}{Y_{s}}\right)(1-\kappa)\left(1-e^{-(1+\chi) u_{t}}\right) \varpi^{t-s-1}$,

which encodes the (normalized) value of growth options. 
The maintained conjecture that $\xi_{t+1} / \xi_{t}$ is a deterministic function of $\varepsilon_{t+1}$ and $u_{t+1}$ and Eq. (21) imply that $\theta^{e}$ and $\theta^{g}$ are both constants. Using (22) inside (15),

$c_{s, s}^{e}=\frac{\theta^{e}}{\phi} \frac{\alpha(1-\alpha) Y_{s}}{\lambda}\left\{\kappa\left(1-e^{-(1+\chi) u_{s}}\right)+(1-\varpi) \theta^{g}\right\}$.

Combining (57) and (62) and noting that $s$ in Eqs. (62) and (57) is arbitrary, we obtain

$$
\begin{gathered}
\sum_{i \in\{w, e\}} \phi^{i} \frac{c_{t+1, t+1}^{i}}{Y_{t+1}}=\theta^{e} \frac{1}{\lambda}\left\{\kappa\left(1-e^{-(1+\chi) u_{t+1}}\right)+(1-\varpi) \theta^{g}\right\} \alpha(1-\alpha) \\
+\bar{h} \theta^{w}\left(1-(1-\lambda)(1+\delta) e^{-\rho u_{t+1}}\right)\left(\alpha^{2}+1-\alpha\right),
\end{gathered}
$$

which is a deterministic function of $u_{t+1}$. Using (63) and $\bar{h}=1 / \lambda$ inside $(25)$ verifies the conjecture that there exists an equilibrium with $\xi_{t+1} / \xi_{t}=\beta\left(Y_{t+1} / Y_{t}\right)^{-1+\psi(1-\gamma)} \times$ $f\left(u_{t+1}\right)$ where $f\left(u_{t+1}\right)$ is given by $f\left(u_{t+1}\right)=[(1 /(1-\lambda))$ $\left.v\left(u_{t+1} ; \theta^{e}, \theta^{w}, \theta^{g}\right)\right]^{-\gamma}$. This proves Eq. (55).

To obtain Eqs. (51)-(53), we use the formula (55) for the growth of the stochastic discount factor in the definitions (58), (60), and (61). We start by computing the term inside square brackets in Eq. (59). Since $\left(\xi_{i+1} / \xi_{i}\right)$ $\left(\pi_{j, i+1}^{I} / \pi_{j, i}^{I}\right)$ is an i.i.d. random variable for any $i$, it follows that

$$
\begin{aligned}
\mathrm{E}_{s} \sum_{t=s}^{\infty}\left(\frac{\xi_{t}}{\xi_{s}}\right)\left(\frac{\pi_{j, t}^{I}}{\pi_{j, s}^{I}}\right)=\sum_{t=s}^{\infty} \mathrm{E}_{s}\left(\frac{\xi_{t}}{\xi_{s}}\right)\left(\frac{\pi_{j, t}^{I}}{\pi_{j, s}^{I}}\right) \\
=\sum_{t=s}^{\infty} \mathrm{E}_{s} \prod_{i=s}^{t-1}\left(\frac{\xi_{i+1}}{\xi_{i}}\right)\left(\frac{\pi_{j, i+1}^{I}}{\pi_{j, i}^{I}}\right)=\sum_{t=s}^{\infty} \prod_{i=s}^{t-1} \mathrm{E}_{s}\left(\frac{\xi_{i+1}}{\xi_{i}}\right)\left(\frac{\pi_{j, i+1}^{I}}{\pi_{j, i}^{I}}\right) \\
=\sum_{t=s}^{\infty}\left[\mathrm{E}_{s}\left(\frac{\xi_{s+1}}{\xi_{s}}\right)\left(\frac{\pi_{j, s+1}^{I}}{\pi_{j, s}^{I}}\right)\right]^{t-s}=\frac{1}{1-\mathrm{E}_{s}\left(\frac{\xi_{s+1}}{\xi_{s}}\right)\left(\frac{\pi_{j, s+1}^{I}}{\pi_{j, s}^{I}}\right)}
\end{aligned}
$$

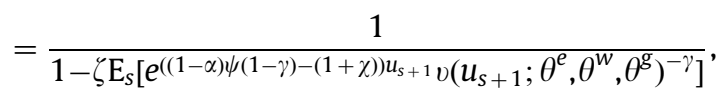

where the last equality follows from (55):

$$
\begin{aligned}
\mathrm{E}_{s} & {\left[\frac{\xi_{s+1}}{\xi_{s}} \frac{\pi_{j, s+1}^{I}}{\pi_{j, s}^{I}}\right] } \\
& =\beta \mathrm{E}_{s}\left[\left(e^{\left(\mu+\varepsilon_{s+1}\right)} e^{(1-\alpha) u_{s+1}}\right)^{\psi(1-\gamma)-1}\left(e^{\left(\mu+\varepsilon_{s+1}\right)} e^{-(\alpha+\chi) u_{s+1}}\right)\right. \\
& \left.\times\left(\frac{1}{1-\lambda} v\left(u_{t+1} ; \theta^{e}, \theta^{w}, \theta^{g}\right)\right)^{-\gamma}\right] \\
& =\beta \mathrm{E}_{s}\left[e^{\psi(1-\gamma)\left(\mu+\varepsilon_{s+1}\right)} e^{((1-\alpha) \psi(1-\gamma)-(1+\chi)) u_{s+1}}\right. \\
& \left.\times\left(\frac{1}{1-\lambda} v\left(u_{t+1} ; \theta^{e}, \theta^{w}, \theta^{g}\right)\right)^{-\gamma}\right] .
\end{aligned}
$$

Following a similar reasoning,

$$
\begin{aligned}
\mathrm{E}_{S} \sum_{t=s}^{\infty}(1-\lambda)^{t-s}\left(\frac{\xi_{t}}{\xi_{s}}\right)\left(\frac{w_{t}}{w_{s}}\right)(1+\delta)^{t-s}\left(\frac{A_{t}}{A_{s}}\right)^{-\rho} \\
\quad=\frac{1}{1-(1-\lambda)(1+\delta) \zeta \mathrm{E}_{S}\left[e^{\left.((1-\alpha) \psi(1-\gamma)-\rho) u_{s+1} v\left(u_{s+1} ; \theta^{e}, \theta^{w}, \theta^{g}\right)^{-\gamma}\right]}\right.}
\end{aligned}
$$

and

$$
\begin{aligned}
& \mathrm{E}_{s} \sum_{t=s}^{\infty}(1-\lambda)^{t-s}\left(\frac{\xi_{t}}{\xi_{s}}\right)\left(\frac{Y_{t}^{(1-\psi)(1-\gamma)}}{Y_{s}^{(1-\psi)(1-\gamma)}} \beta^{-(t-s)} \frac{\xi_{t}}{\xi_{s}}\right)^{-1 / \gamma}
\end{aligned}
$$

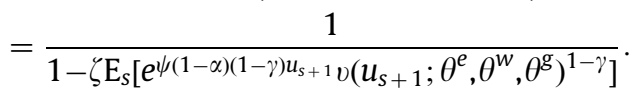

Finally,

$$
\begin{aligned}
& \mathrm{E}_{s} \sum_{t=s+1}^{\infty}\left(\frac{\xi_{t}}{\xi_{s}}\right)\left(\frac{Y_{t}}{Y_{s}}\right)\left(1-e^{-(1+\chi) u_{t}}\right)(1-\kappa) \varpi^{t-s-1} \\
&=\mathrm{E}_{s} \sum_{t=s+1}^{\infty}\left[\prod_{i=s+1}^{t}\left(\frac{\xi_{i}}{\xi_{i-1}}\right)\left(\frac{Y_{i}}{Y_{i-1}}\right) \varpi \varpi^{-1}\left(1-e^{-(1+\chi) u_{t}}\right)(1-\kappa)\right. \\
&=\sum_{t=s+1}^{\infty} \mathrm{E}_{s}\left\{\left[\prod_{i=s+1}^{t-1}\left(\frac{\xi_{i}}{\xi_{i-1}}\right)\left(\frac{Y_{i}}{Y_{i-1}}\right) \varpi\right]\right. \\
&\left.\quad \times\left(\frac{\xi_{t}}{\xi_{t-1}}\right)\left(\frac{Y_{t}}{Y_{t-1}}\right)\left(1-e^{-(1+\chi) u_{t}}\right)(1-\kappa)\right\} \\
&=\sum_{t=s+1}^{\infty}\left\{\prod_{i=s+1}^{t-1} \mathrm{E}_{s}\left(\frac{\xi_{i}}{\xi_{i-1}}\right)\left(\frac{Y_{i}}{Y_{i-1}}\right) \varpi\right\} \\
& \times \mathrm{E}_{t}\left[\left(\frac{\xi_{t+1}}{\xi_{t}}\right)\left(\frac{Y_{t+1}}{Y_{t}}\right)\left(1-e^{-(1+\chi) u_{t+1}}\right)(1-\kappa)\right] \\
&= \frac{\zeta \mathrm{E}_{s}\left[e^{\left.(1-\alpha) \psi(1-\gamma) u_{s+1} v\left(u_{s+1} ; \theta^{e}, \theta^{w}, \theta^{g}\right)^{-\gamma}\left(1-e^{-(1+\chi) u_{s+1}}\right)(1-\kappa)\right]}\right.}{1-\varpi \zeta \mathrm{E}_{s}\left\{e^{\left.(1-\alpha) \psi(1-\gamma) u_{s+1} v\left(u_{s+1} ; \theta^{e}, \theta^{w}, \theta^{g}\right)^{-\gamma}\right\}} .\right.} .
\end{aligned}
$$

Combining (67) with (61) leads to (53). Similarly, combining (60) with (66) and (64) leads to (51), while combining (58), (65), and (66) implies (52).

Proof of Lemma 1. To establish that the equity premium is nonzero in the limit, it suffices to show that

$\lim _{\alpha \rightarrow 1} \operatorname{cov}\left\{R_{t+1},\left(\xi_{t+1} / \xi_{t}\right)\right\} \neq 0$.

Since $\kappa=1$, all stocks have rate of return

$R_{t+1}=\left(\frac{\pi_{t+1}^{I}}{\pi_{t}^{I}}\right)\left(\frac{1+\frac{\Pi_{t+1}^{I}}{\pi_{t+1}^{I}}}{\frac{\Pi_{t}^{I}}{\pi_{t}^{I}}}\right)$

Eq. (59) implies that $\left(\Pi_{t}^{I} / \pi_{t}^{I}\right)$ is a constant. Therefore, in order to establish (68), it suffices to show that $\lim _{\alpha \rightarrow 1} \operatorname{cov}\left(\left(\pi_{t+1}^{I} / \pi_{t}^{I}\right),\left(\xi_{t+1} / \xi_{t}\right)\right) \neq 0$. To see that this is the case, note that $\lim _{\alpha \rightarrow 1}\left(\pi_{t+1}^{I} / \pi_{t}^{I}\right)=e^{\mu-(1+\chi) u_{t+1}}$. Hence, in order to establish (68), we need to show that $\xi_{t+1} / \xi_{t}$ is a non-degenerate function of $u_{t+1}$ as $\alpha \rightarrow 1$. Given that

$$
\begin{aligned}
\lim _{\alpha \rightarrow 1}\left(\frac{\xi_{t+1}}{\xi_{t}}\right)= & \beta(1-\lambda)^{\gamma} e^{\mu(-1+\psi(1-\gamma))} \\
& \times\left[1-\theta^{w}\left(1-(1-\lambda)(1+\delta) e^{-\rho u_{t+1}}\right)\right]^{-\gamma},
\end{aligned}
$$

the lemma holds as long as a solution $\theta^{w}>0$ exists to Eq. (52), an equation that simplifies to

$$
\begin{aligned}
& \theta^{w}\left(1-\zeta(1-\lambda)(1+\delta) \mathrm{E}\left[e^{-\rho u}\left(1-\theta^{w}\left(1-(1-\lambda)(1+\delta) e^{-\rho u_{t}}\right)\right)^{-\gamma}\right]\right) \\
& \quad=1-\zeta \mathrm{E}\left[\left(1-\theta^{w}\left(1-(1-\lambda)(1+\delta) e^{-\rho u_{t}}\right)\right)^{1-\gamma}\right] .
\end{aligned}
$$

By expanding the right-hand side of (70), the equation further simplifies to

$$
1=\zeta \mathrm{E}\left[\left(1-\theta^{w}\left(1-(1-\lambda)(1+\delta) e^{-\rho u_{t}}\right)\right)^{-\gamma}\right] .
$$

As the right-hand side increases in $\theta^{w}$, and the probability of the event $\left\{u_{t} \in(0, \epsilon)\right\}$ is strictly positive for all $\varepsilon>0$, 
conditions (27) and (28) are necessary and sufficient for the existence of a solution $\theta^{w}>0$. (Note that $\theta^{w} \leq 1$.)

Proof of Lemma 2. Without loss of generality, we focus on the representative growth firm. (A value firm is a special case of a growth firm with no growth opportunities.) We start by showing the following result.

Lemma 4. The (end of) period-t value of the representative growth firm created at time $s$ is given by

$P_{t, s}=\alpha(1-\alpha) Y_{t}\left[(\Phi-1) N_{t, s}+(1-\varpi) \varpi^{t-s} \theta^{g} \Phi\right]$,

where

$$
\begin{aligned}
N_{t, s} & =(1-\eta) \kappa\left(\frac{A_{s}}{A_{t}}\right)^{1+\chi}\left(1-e^{-(1+\chi) u_{s}}\right) \\
& +\sum_{n=s+1}^{t}(1-\varpi)(1-\kappa) \varpi^{n-(s+1)}\left(\frac{A_{n}}{A_{t}}\right)^{1+\chi}\left(1-e^{-(1+\chi) u_{n}}\right) .
\end{aligned}
$$

Proof of Lemma 4. The value of a growth firm is given by the value of all its assets in place and all its growth options.

$$
\begin{aligned}
P_{t, s}= & (1-\eta) \kappa\left(\int_{A_{s-1}}^{A_{s}} \Pi_{j, t}^{I} d j\right) \\
& +\sum_{n=s+1}^{t}(1-\varpi)(1-\kappa) \varpi^{n-(s+1)}\left(\int_{A_{n-1}}^{A_{n}} \Pi_{j, t}^{I} d j\right) \\
& +(1-\varpi)\left[\mathrm{E}_{t} \sum_{n=t+1}^{\infty}\left(\frac{\xi_{n}}{\xi_{t}}\right) \varpi^{n-(s+1)}\left(\int_{A_{n-1}}^{A_{n}} \Pi_{j, n}^{I} d j\right)(1-\kappa)\right] .
\end{aligned}
$$

Using the definition of $\Phi$ and noting that $\int_{A_{s-1}}^{A_{s}} \pi_{j, t}^{I} d j=\left(A_{s} / A_{t}\right)^{1+\chi}\left(1-e^{-(1+\chi) u_{s}}\right)$ along with the definition of $\theta^{g}$ in Eq. (61) leads to (72).

The gross return on a growth firm $R_{t+1}^{g}$ at time $t+1$ is given by sum of the time- $t+1$ dividends from all the blueprints collected by the firm up to and including period $t+1, \alpha(1-\alpha) Y_{t+1} N_{t+1, s}$, and the end-of-period price $P_{t+1, s}$, divided by the beginning-of-period price $P_{t, s}$ :

$R_{t+1, s}^{g} \equiv \frac{\alpha(1-\alpha) Y_{t+1} N_{t+1, s}+P_{t+1, s}}{P_{t, s}}$.

Using the definitions of $R_{t+1}^{a}$ and $R_{t+1}^{o}$, as given in the statement of the lemma, the gross rate of return on any growth firm can be expressed as in Eq. (34), where $w_{t, s}^{o}$ is the relative weight of growth opportunities in the value of the firm, and is obtained from Lemma 4 as

$w_{t, s}^{o}=\frac{(1-\varpi) \varpi^{t-s} \theta^{g} \Phi}{(\Phi-1) N_{t, s}+(1-\varpi) \varpi^{t-s} \theta^{g} \Phi}$.

Combining (21) and (20) with (32) and (33), we obtain that the return on assets in place has a negative loading on the innovation shock, $\partial R_{t+1}^{a} / \partial u_{t+1}<0$, while the return on the growth-opportunity component of the firm value has a positive loading, $\partial R_{t+1}^{o} / \partial u_{t+1}>0$.

Proof of Lemma 3. Eq. (37) implies that

$$
\begin{aligned}
& a_{s+1}^{i}-a_{s}^{i}=\log c_{s+1, s+1}^{i}-\log c_{s, s}^{i} \\
& \quad+\frac{1}{\gamma} \log \left(C_{s+1}^{(1-\psi)(1-\gamma)} \beta^{-(s+1)} \xi_{s+1}\right)-\frac{1}{\gamma} \log \left(C_{s}^{(1-\psi)(1-\gamma)} \beta^{-s} \xi_{s}\right) .
\end{aligned}
$$

Using (55) inside (73) along with $C_{s}=Y_{s}$ and simplifying gives

$$
\begin{gathered}
a_{s+1}^{i}-a_{s}^{i}=\log c_{s+1, s+1}^{i}-\log c_{s, s}^{i}-\log \left(\frac{C_{s+1}}{C_{s}}\right) \\
-\log \left[\frac{1}{1-\lambda} v\left(u_{s+1} ; \theta^{e}, \theta^{w}, \theta^{g}\right)\right] .
\end{gathered}
$$

Using the definitions of $a_{s}$ and $z_{s}$, (57), and (62), noting that $C_{s}=Y_{s}$, and simplifying gives

$$
a_{s+1}-a_{s}=-\log \left[\frac{1}{1-\lambda} v\left(u_{s+1} ; \theta^{e}, \theta^{w}, \theta^{g}\right)\right]+z_{s+1}-z_{s} .
$$

Eq. (40) follows immediately.

\section{Appendix B. Data description}

The CEX data are from the NBER Web site as compiled by Ed Harris and John Sabelhaus. See http://www.nber. org/ces_cbo/Cexfam.pdf for a detailed description of the data. In short, the data set compiles the results from the four consecutive quarterly interviews in the CEX into one observation for each household. We follow a large literature (see, e.g., Vissing-Jorgensen, 2002) and drop from the sample households with incomplete income responses, households that have not completed one of the quarterly interviews, and households that reside in student housing. To ensure that data selection does not unduly affect the results, we also ran all the regressions on the raw data including dummies for reporting status and the number of completed interview quarters. The results were not affected in any essential way.

In terms of our definition of consumption, we followed Fernandez-Villaverde and Krueger (2007) and used a comprehensive measure of consumption expenditure. Specifically, we used exactly the same definition as Harris and Sabelhaus. Our choice is motivated by our model; according to the model, cohort effects are determined by the intertemporal budget constraint of agents born at different times, so that total consumption expenditure seems to be the appropriate concept for the estimation of cohort effects. To test if this choice materially affects our conclusions, we also ran the results using consumption of non-durables and services instead of total consumption expenditure. Using consumption of non-durables and services, the volatility of first differences of cohort effects was larger; however, there was not a big difference in the variance of the permanent components of the cohort effects, no matter which concept of consumption we used, consistent with the view that the two estimates of cohort effects share the same stochastic trend.

\section{Appendix C. Supplementary data}

Supplementary data associated with this article can be found in the online version at http://dx.doi.org.10.1016/j. jfineco.2012.04.002.

\section{References}

Abel, A.B., 1990. Asset prices under habit formation and catching up with the Joneses. American Economic Review 80, 38-42. 
Abel, A.B., 2003. The effects of a baby boom on stock prices and capital accumulation in the presence of social security. Econometrica 71 , 551-578.

Abel, A.B., Kotlikoff, L.J., 2001. Intergenerational altruism and the effectiveness of fiscal policy - new tests based on cohort data. In: Kotlikoff, L. (Ed.), Essays on Saving, Bequests, Altruism, and Life-Cycle Planning, MIT press, Cambridge and London, pp. 177-209.

Attanasio, O., Davis, S.J., 1996. Relative wage movements and the distribution of consumption. Journal of Political Economy 104, 1227-1262.

Barro, R.J., 2006. Rare disasters and asset markets in the twentieth century. Quarterly Journal of Economics 121, 823-866.

Basak, S., Cuoco, D., 1998. An equilibrium model with restricted stock market participation. Review of Financial Studies 11, 309-341.

Berk, J.B., Green, R.C., Naik, V., 1999. Optimal investment, growth options, and security returns. Journal of Finance 54, 1553-1607.

Beveridge, S., Nelson, C.R., 1981. A new approach to decomposition of economic time series into permanent and transitory components with particular attention to measurement of the 'business cycle'. Journal of Monetary Economics 7, 151-174.

Blanchard, O.J., 1985. Debt, deficits, and finite horizons. Journal of Political Economy 93, 223-247.

Campbell, J.Y., Cochrane, J.H., 1999. By force of habit: a consumptionbased explanation of aggregate stock market behavior. Journal of Political Economy 107, 205-251.

Carlson, M., Fisher, A., Giammarino, R., 2004. Corporate investment and asset price dynamics: implications for the cross-section of returns. Journal of Finance 59, 2577-2603.

Carlson, M. Fisher, A., Giammarino, R, 2006. Corporate investment and asset price dynamics: implications for seo event studies and longrun performance. Journal of Finance 61, 1009-1034.

Cogley, T., 2002. Idiosyncratic risk and the equity premium: evidence from the consumer expenditure survey. Journal of Monetary Economics 49, 309-334.

Constantinides, G.M., Donaldson, J.B., Mehra, R., 2002. Junior can't borrow: a new perspective of the equity premium puzzle. Quarterly Journal of Economics 117, 269-296.

Constantinides, G.M., Duffie, D., 1996. Asset pricing with heterogeneous consumers. Journal of Political Economy 104, 219-240.

Deaton, A., Paxson, C., 1994. Intertemporal choice and inequality. Journal of Political Economy 102, 437-467.

DeMarzo, P.M., Kaniel, R., Kremer, I., 2004. Diversification as a public good: community effects in portfolio choice. Journal of Finance 59, 1677-1715.

DeMarzo, P.M., Kaniel, R., Kremer, I., 2008. Relative wealth concerns and financial bubbles. Review of Financial Studies 21, 19-50.

Fama, E.F., French, K.R., 1992. The cross-section of expected stock returns. Journal of Finance 47, 427-465

Fama, E.F., French, K.R., 1993. Common risk factors in the returns on stock and bonds. Journal of Financial Economics 33, 3-56.

Fama, E.F., French, K.R., 1995. Size and book-to-market factors in earnings and returns. Journal of Finance 50, 131-155.

Fernandez-Villaverde, J., Krueger, D., 2007. Consumption over the life cycle: facts from consumer expenditure survey data. Review of Economics and Statistics 89, 552-565.

Gala, V.D., 2005. Investment and returns. Unpublished working paper. University of Chicago.

Gârleanu, N., Panageas, S., 2007. Young, old, conservative and bold: the implications of finite lives and heterogeneity for asset pricing. Unpublished working paper. University of Chicago and University of California, Berkeley.
Geanakoplos, J., Magill, M., Quinzii, M., 2004. Demography and the longrun predictability of the stock market. Brookings Papers on Economic Activity 1, 241-307.

Gomes, F., Michaelides, A., 2008. Asset pricing with limited risk sharing and heterogeneous agents. Review of Financial Studies 21, 415-449.

Gomes, J., Kogan, L., Zhang, L., 2003. Equilibrium cross section of returns. Journal of Political Economy 111, 693-732.

Gort, M., Klepper, S., 1982. Time paths in the diffusion of product innovations. Economic Journal 92, 630-653.

Greenwood, J., Uysal, G., 2005. New goods and the transition to a new economy. Journal of Economic Growth 10, 99-134.

Grossman, S.J., Shiller, R.J., 1982. Consumption correlatedness and risk measurement in economies with non-traded assets and heterogeneous information. Journal of Financial Economics 10, 195-210.

Hansen, L.P., Heaton, J.C., Li, N., 2008. Consumption strikes back? Measuring long-run risk. Journal of Political Economy 116, 260-302.

Heaton, J., Lucas, D.J., 1996. Evaluating the effects of incomplete markets on risk sharing and asset pricing. Journal of Political Economy 104, 443-487.

Hobijn, B., Jovanovic, B., 2001. The information-technology revolution and the stock market: evidence. American Economic Review 91, 1203-1220.

Hubbard, G.R., Skinner, J., Zeldes, S.P., 1994. The importance of precautionary motives for explaining individual and aggregate saving. Carnegie-Rochester Conference Series on Public Policy 40, 1-67.

Imrohoroglu, A., Tuzel, S., 2011. Firm level productivity, risk and return. Unpublished working paper. University of Southern California.

Jones, C.I., 1997. Introduction to Economic Growth, first ed. W.W. Norton, New York, London.

Jovanovic, B., MacDonald, G.M., 1994. The life cycle of a competitive industry. Journal of Political Economy 102, 322-347.

Klepper, S., Graddy, E., 1990. The evolution of new industries and the determinants of market structure. RAND Journal of Economics 21, 27-44.

Krueger, D., Lustig, H., 2010. When is market incompleteness irrelevant for the price of aggregate risk (and when is it not)? Journal of Economic Theory 145, 1-41.

Krusell, P., Ohanian, L.E., Ríos-Rull, J.-V., Violante, G.L., 2000. Capital-skill complementarity and inequality: a macroeconomic analysis. Econometrica 68, 1029-1053.

Luttmer, E.G., 2007. Selection, growth, and the size distribution of firms. Quarterly Journal of Economics 122, 1103-1144.

McKenzie, D.J., 2006. Disentangling age, cohort and time effects in the additive model. Oxford Bulletin of Economics and Statistics 68, 473-495.

Mehra, R., Prescott, E.C., 1985. The equity premium: a puzzle. Journal of Monetary Economics 15, 145-161.

Papanikolaou, D., 2007. Investment-specific shocks and asset prices. Unpublished working paper. Kellogg.

Politis, D., Romano, J., 1994. The stationary bootstrap. Journal of Monetary Economics 89, 1303-1313.

Romer, P.M., 1990. Endogenous technological change. Journal of Political Economy 98, 71-102.

Storesletten, K., Telmer, C.I., Yaron, A., 2007. Asset pricing with idiosyncratic risk and overlapping generations. Review of Economic Dynamics 10, 519-548.

Vissing-Jorgensen, A., 2002. Limited asset market participation and the elasticity of intertemporal substitution. Journal of Political Economy $110,825-853$.

Zhang, L., 2005. The value premium. Journal of Finance 60, 67-103. 